Article

\title{
The Effect of Antioxidant Supplementation in Patients with Tinnitus and Normal Hearing or Hearing Loss: A Randomized, Double-Blind, Placebo Controlled Trial
}

\author{
Anna I. Petridou ${ }^{1}$, Eleftheria T. Zagora ${ }^{2}$, Petros Petridis ${ }^{3}$, George S. Korres ${ }^{4} \oplus$, Maria Gazouli ${ }^{5} \oplus$, \\ Ioannis Xenelis ${ }^{1}$, Efthymios Kyrodimos ${ }^{1}$, Georgia Kontothanasi ${ }^{2}$ and Andriana C. Kaliora ${ }^{6, *}$ \\ 1 1st ENT Department, School of Medicine, National and Kapodistrian University of Athens, \\ Hippokration Hospital, 11527 Athens, Greece; anna.petridou@outlook.com (A.I.P.); \\ cxeneli@yahoo.com (I.X.); timkirodimos@hotmail.com (E.K.) \\ 2 ENT Department, General Hospital of Nikaia "Agios Panteleimon”, Nikaia, 18454 Athens, Greece; \\ zagoraeleftheria@gmail.com (E.T.Z.); georgia.kontothanasi@gmail.com (G.K.) \\ 3 ENT Department, St. Johannes Hospital, 44137 Dortmund, Germany; petridispppeter@hotmail.com \\ 4 2nd ENT Department, School of Medicine, National and Kapodistrian University of Athens, \\ Attikon Hospital, 12462 Chaidari, Greece; gfkorres@gmail.com \\ 5 Department of Biology, School of Medicine, National and Kapodistrian University of Athens, \\ 11527 Athens, Greece; maria.gazouli@gmail.com \\ 6 Department of Dietetics and Nutritional Science, School of Health Science and Education, \\ Harokopio University, 17671 Athens, Greece \\ * Correspondence: akaliora@hua.gr or rianakaliora@gmail.com; Tel.: +30-210-954-9226
}

Received: 7 November 2019; Accepted: 3 December 2019; Published: 12 December 2019

\begin{abstract}
Tinnitus is the perception of sound in the absence of any external stimulus. Oxidative stress is possibly involved in its pathogenesis and a variety of antioxidant compounds have been studied as potential treatment approaches. The objective of the present study was to assess the effects of antioxidant supplementation in tinnitus patients. This is a randomized, double-blind, placebo-controlled clinical trial. Patients $(N=70)$ were randomly allocated to antioxidant supplementation $(N=35)$ or to placebo $(N=35)$ for a total of 3 months. Demographic, anthropometric, clinical, and nutritional data were collected. Serum total antioxidant capacity (TAC), oxidized LDL (oxLDL), and superoxide dismutase (SOD), tinnitus loudness, frequency, and minimum masking level (MML), and scores in Tinnitus Handicap Inventory questionnaire (THI), Tinnitus Functional Index (TFI), and Visual Analogue Scale (VAS) were evaluated at baseline and follow-up. Tinnitus loudness and MML significantly decreased from baseline to post measure $(p<0.001)$ only in the antioxidant group, the overall change being significantly different between the two groups post-intervention $(p<0.001)$. THI and VAS decreased only in the antioxidant group. Differences in changes in serum TAC, SOD, and oxLDL post-intervention were insignificant. In conclusion, antioxidant therapy seems to reduce the subjective discomfort and tinnitus intensity in tinnitus patients.
\end{abstract}

Keywords: tinnitus; antioxidant supplementation; oxidative stress; a-lipoic acid; multi-vitamin supplement

\section{Introduction}

Tinnitus is the perception of sound in the absence of any external stimulus [1]. Its prevalence is estimated at approximately $10 \%-15 \%$ of the adult population and its impact varies from a mild perception to a severe disturbance in everyday life [2]. Causes of tinnitus remain unknown and the 
pathological mechanisms are not fully understood. Currently, no drug treatment is effective, whereas the treatment approaches described in literature provide different results [2].

Oxidative stress has been proposed to play a critical role in the pathogenesis of tinnitus, since it could lead to cellular changes in hair cells, hair cell apoptosis, cochlear degeneration, changes in supporting structures and stria vascularis, changes in nerve fibers of the acoustic nerve, irregular neural activity in the auditory pathway and dysfunction of the central cortex [3-5]. Hair cell apoptotic pathways linked to oxidative stress have been studied in animal models in conditions of aging, noise trauma and ototoxicity [3]. Oxidative stress activates mitogen-activated protein kinase/c-Jun $\mathrm{N}$-terminal kinase (MAPK/JNK) pathway, which subsequently leads to the release of cytochrome c from mitochondria $[3,6]$. Cytochrome c causes mitochondrial membrane damage and activates caspase pathway, promoting apoptosis [3,6]. In organ of Corti cultures, low dose oxidative stress has been shown to induce mitochondrial DNA (mtDNA) deletions in hair cells, which make them more vulnerable to further injury [7]. Moreover, oxidative stress may be linked to endothelial damage within cochlear microcirculation [8].

Higher plasma concentrations of oxidative stress biomarkers and lower antioxidant activity have been reported in tinnitus patients compared with healthy subjects [8-12]. However, research data on the efficacy of antioxidant supplementation in tinnitus are limited and conflicting. Moreover, oxidative stress biomarkers have not been assessed in most studies. Gingko Biloba, a rich source of flavonoids, has been shown to reduce the subjective discomfort and intensity of tinnitus $[13,14]$. Additionally, preliminary outcomes of a brief report have shown that an 18-week supplementation with antioxidants and phospholipids regulated oxidative stress and reduced the subjective discomfort and intensity of tinnitus [15]. However, other studies failed to show any benefit [16,17].

A great deal of the protective mechanisms of antioxidants against cochlea damage has been identified from animal models For example, alpha-lipoic acid (ALA) has been shown to provide protection from noise-induced hearing loss in animal models [18,19]. Moreover, many experimental studies have proven the protective effect of polyphenols against cisplatin-induced ototoxicity [20-22] and cochlear hair cell damage after intense noise exposure [23-25]. In human studies, vitamin E has been shown effective in the treatment of sudden idiopathic hearing loss [26] and ALA in the prevention of noise-induced hearing loss [27].

The aim of the study was to explore the efficacy of antioxidant supplementation which provides vitamins, minerals, and phytochemicals combined with ALA on tinnitus parameters and subjective discomfort. A second aim was to assess whether antioxidant administration had an impact on biomarkers of oxidative stress.

\section{Materials and Methods}

\subsection{Study Design}

The study protocol was reviewed and approved by the Scientific Council of the General Hospital of Athens, "Hippocratio" (11888/24-6-2009) and it was conducted according to the principles of the Declaration of Helsinki of 1975 as revised in 2013.

This was a randomized, double-blind, placebo-controlled, parallel group clinical trial (Appendix A). The trial was registered with ClinicalTrials.gov (Identifier: NCT04105426).

The primary endpoint was change in tinnitus loudness. The secondary endpoints were changes in tinnitus frequency and MML, the impact of tinnitus on daily life, hearing thresholds, and serum oxidative stress biomarkers. Tinnitus patients were enrolled based on certain inclusion and exclusion criteria. Both males and females, aged between 25 and 75 years old, with chronic unilateral or bilateral persistent tinnitus of at least 6 months' duration, with normal hearing or up to moderate sensorineural hearing loss were included. Tinnitus maskable with noise of at least 5 decibel and a score of minimum 4 in Tinnitus Handicap Inventory (THI) questionnaire were set as inclusion criteria. Patients whose tinnitus resulted from acute acoustic trauma, sudden deafness or traumatic head or 
neck injury were excluded from trial enrolment. Patients who were taking ototoxic or potentially tinnitus-inducing medication (e.g., aminoglycosides, chemotherapeutics, loop diuretics, high doses of aspirin or quinine) were also excluded. Moreover, patients with Meniere's disease, otosclerosis and acute or chronic otitis media were excluded. Gastrointestinal disease, active malignant diseases, autoimmune diseases, hemorrhagic diathesis, cardiovascular, renal or hepatic disorders, psychiatric disorders, and unregulated diabetes mellitus, hypertension, or thyroid disease were also set as exclusion criteria. Additionally, alcohol or drug abuse, dietary supplement use, a vegan or macrobiotic diet $<2$ years prior to screening, pregnancy and lactation were exclusion criteria. Patients who changed their medication, diet or physical activity habits during the trial were also excluded.

One hundred patients registered in medical archives with the symptom of tinnitus were invited for screening. An Ear Nose and Throat (ENT) physician, unrelated to the project, took a complete medical and tinnitus history followed by an ENT review examination including an audiological evaluation. Audiological assessment included conventional pure tone audiometry (PTA), tympanometry and brainstem response (BSR). Moreover, a computer tomography scanning (CT) and magnetic resonance imaging (MRI) were conducted where appropriate, in order to exclude any retrocochlear lesion. Seventy patients were eligible for the study, based on the above criteria. The ENT physician informed the eligible patients regarding the aims, methods, anticipated benefits and potential hazards of the study, and provided them with the information leaflet of the study. Each patient who agreed to take part in the study, signed an informed consent form, a copy of which was given to them.

After the initial screening, participants were randomly allocated to an intervention, either active or placebo. Randomization was conducted by an unrelated to the study person, who prepared a random number list in the computer. Neither the participants nor the investigators were aware of the treatment allocation.

The antioxidant group received one multivitamin-multimineral tablet once a day with their meal and one tablet of alpha-lipoic acid twice a day on an empty stomach, whereas the placebo group received three placebo tablets per day at the same time points. To prevent any acute supplementation effects, participants were asked not to take any tablets on the day of the follow-up measurements. To check upon compliance, each participant was seen monthly by a research coordinator who checked the compliance and tolerance of the supplement. Additionally, blood levels of vitamins and minerals were estimated in all participants before and after the intervention.

The dietary supplements received by the antioxidant group are commercially available. A-lipoic acid supplement contained $300 \mathrm{mg}$ a-lipoic acid per tablet. The ingredients of the multivitamin-multimineral supplement are shown in Appendix B. The nutritional supplementation doses in the multivitamin-multimineral supplement were in line with or above the Recommended Dietary Allowances and Adequate Intakes (RDA) [28] and did not exceed the Tolerable Upper Intake Levels (UL) [29]. These doses are commonly available in commercial multivitamin supplements. Placebo pills were produced by a local manufacturing pharmacy according to good manufacturing practice (GMP) and contained sorbitol. They were manufactured with similar shape and color to the other supplements.

Dietary supplements and placebo pills were packaged in bottles and then in bags of identical appearance and labeled with the participant's number by an investigator who was not involved in the study. The bags were given to participants by an independent investigator. Instructions for the consumption of pills were included in the bags.

The intervention lasted 3 months. Participants were instructed to keep their usual medical treatment, diet, and exercise habits stable during the intervention. Patients were recruited between January 2019 and March 2019. Follow-up visits were completed on May 2019. 


\subsection{Baseline Assessment}

After enrollment, patients underwent a complete baseline assessment which included anthropometric, audiometric, tinnitus psychoacoustic measures, tinnitus discomfort, psychological, physical activity, and dietary assessment as well as blood sample collection.

\subsubsection{Audiometric Assessment and Psychoacoustic Measures of Tinnitus}

Patients underwent conventional pure tone audiometry and extended high frequency (EHF) audiometry, to determine any hearing loss. Pure tones were delivered to the ear where tinnitus was more intense at the frequencies from 250 to $12,000 \mathrm{~Hz}$. Pure tone audiometric threshold (PTA) is the minimum volume required to hear each tone at the examined frequency. PTA thresholds were then plotted on the audiogram. The degree of hearing loss was determined using the average of values in four consecutive frequencies (500-1000-2000-4000) and was classified as normal hearing, mild hearing loss or moderate hearing loss [30]. High frequency hearing loss was determined based on figures of hearing thresholds at extended high frequencies [31].

Moreover, tinnitus assessment tests were conducted, using psychoacoustic techniques which included frequency pitch and loudness matching, as well as minimum masking level (MML) method [32]. When tinnitus was bilateral, tests were performed to the ear where tinnitus was more intense.

Frequency pitch matching test, which determines the possible frequency of tinnitus, was conducted using the two-forced alternative choice procedure. Patients were given pairs of different tones in the ear without or less intense tinnitus and were asked to choose which tone is closer to the perceived tinnitus. This was continued until a definite match was made [32].

Loudness matching test, which determines the loudness of tinnitus, was conducted using the ascending method. Tones close to or exactly the frequency determined with the pitch matching test were presented to the patients in the ear without or less intense tinnitus. The intensity level started from just below threshold and was increased until there was a match to the perceived tinnitus loudness [32].

The MML method, which determines the least intensity needed to just mask patient's tinnitus, was conducted using the ascending method. Tones close to or exactly the frequency determined with the pitch matching test were presented to the ear with tinnitus. The intensity level started from below threshold and was increased until the patient stopped to perceive his/her tinnitus [32].

\subsubsection{Tinnitus Discomfort Assessment}

Patients completed the questionnaires Tinnitus Handicap Inventory (THI), Tinnitus Functional Index (TFI), and the Visual Analogue Scale (VAS), which measure the subjective discomfort a patient experiences because of tinnitus.

THI comprises 25 questions which are divided in functional, emotional, and catastrophic subscales [33]. Total scores of THI range from 0 to 100.

Visual Analogue Scale assessed the annoyance patients experienced because of tinnitus during work, sleep, relaxing, and concentration [34]. Each score of VAS ranged from 0 to 10 and the total score was the mean of the scores.

TFI includes eight subscales which concern different aspects of daily life: Intrusiveness (I), sense of control (SC), cognition (C), sleep (SL), audition (A), relaxation (R), quality of life (Q), and emotions (E) [35]. These sub-scales contribute to a subscale score and to an overall score ranging from 0 to 100.

\subsubsection{Anthropometric Assessment}

All anthropometric measurements were recorded after $\mathrm{a} \geq 12-\mathrm{h}$ fast. Body weight was measured with light clothing and without shoes using a flat scale (Tanita WB-110MA, Tokyo, Japan) and was recorded to the nearest $0.1 \mathrm{~kg}$. Height was measured on a stadiometer (Seca Model 220, Hamburg, Germany) and was recorded to the nearest $0.1 \mathrm{~cm}$. BMI was calculated as weight (in $\mathrm{kg}$ ) divided by height $\mathrm{t}^{2}$ (in $\mathrm{m}^{2}$ ). The waist and hip circumferences were measured using a stretch-resistant tape. 


\subsubsection{Nutrition and Physical Activity Evaluation}

Dietary intake of patients was assessed by a dietitian using the 24-h recall method for 3 nonconsecutive days ( 2 weekdays and 1 weekend) and a Food Frequency Questionnaire [36]. Nutritional data were then analyzed by Nutritionist Pro nutrient analysis software version 5.2.0 (Axxya Systems, Nutritionist Pro, Stafford, TX, USA). Additionally, adherence to the Mediterranean dietary pattern was assessed by the MedDietScore, resulting to a score ranging from 0 to 55 [37]. Physical activity was assessed by a self-administered long form of the International Physical Activity Questionnaire (IPAQ) [38].

\subsubsection{Psychological Assessment}

The Center for Epidemiologic Studies-Depression (CES-D) and Hospital Anxiety and Depression (HADS) scales were used to assess the psychological situation of patients. Both scales are self-administered and validated in Greek language [39,40].

\subsubsection{Blood Sample Collection and Analyses}

Standard blood sampling $(20 \mathrm{~mL})$ was performed through a catheter in an antecubital vein after a $12 \mathrm{~h}$ overnight fast. Freshly drawn blood samples were used for routine biochemical profiles. Serum and plasma were isolated for further processing.

Vitamin D was measured using the Vitamin D Elisa Kit (Vitamin D Elisa Kit, Cayman Chemical Company, Ann Arbor, MI, USA). Folate was measured using a competitive immunoassay according to the instructions of manufacturers (ADVIA Centaur Folate assay, Siemens Healthcare Diagnostics, NY, USA). Iron was determined using the ADVIA Chemistry Iron_2 method (Siemens Healthcare Diagnostics, NY, USA) [41]. Magnesium was measured using the ADVIA Chemistry Magnesium method which is based on the modified xylidyl blue reaction (Siemens Healthcare Diagnostics, Tarrytown, NY, USA) [42]. Vitamin B12 was determined using a competitive immunoassay according to the instructions of manufacturers (ADVIA Centaur VB12 assay, Siemens Healthcare Diagnostics, Tarrytown, NY, USA). Vitamins A, E, C, B1, B2, and B6 were measured applying high performance liquid chromatography (HPLC) according to the instructions of the manufacturer (ClinRep, HPLC kit, Recipe Chemicals, München, Germany). Zinc was determined using Colorimetric method 5-Br-PAPS-Zinc complex with deproteinization according to the instructions of manufacturers (Wako Zinc Test, FUJIFILM Wako Chemicals Europe, Neuss, Germany). Selenium was measured using a methylene blue kinetic catalytic spectrophotometric method (Sigma-Aldrich Chemie GmbH, Taufkirchen, Germany).

The rest of the samples were stored at $-80^{\circ} \mathrm{C}$ for subsequent analyses.

\subsection{Follow-Up Assessment}

Compliance and any side effects were checked with a weekly telephone contact. Adherence to supplementation was assessed by counting the remaining pills in the package of each participant at the end of the intervention. At the end of the intervention, all baseline assessments were repeated apart from the psychological and physical activity assessment.

\subsection{Oxidative Stress Biomarkers}

Analyses of oxidative stress and antioxidant capacity biomarkers were performed in the Lab of Biology in Medical School of National and Kapodistrian University of Athens.

Serum total antioxidant capacity (TAC) was measured using the Trolox Equivalent Antioxidant Capacity (TEAC) method according to the instructions of the manufacturer (Cayman Antioxidant Assay Kit, Cayman Chemical Company, Ann Arbor, MI, USA). Serum Superoxide Dismutase (SOD) activity was assessed by measuring the dismutation of superoxide radicals generated by xanthine oxidase and hypoxanthine (Cayman Superoxide Dismutase kit, Cayman Chemical Company, Ann Arbor, MI, USA). Oxidized low-density lipoprotein LDL (oxLDL) was measured by a sandwich enzyme-linked 
immune-sorbent assay (Human OxLDL ELISA kit, Wuhan Fine Biological Technology, Wuhan, China). Samples and standards were run in duplicate. A Biotek PowerWave XS2 ELISA reader (BioTek Instruments, Winooski, VT, USA) was used for all measurements and analysis.

\subsection{Sample Size Determination}

Power analysis methodology represents a design, with two levels of the between-subject factor of two study groups and two levels of the within-subjects factor of time. A repeated measures ANOVA power analysis was conducted. The effect size for this calculation used the ratio of the standard deviation of the effects for a particular factor or interaction and the standard deviation of within-subject effects. The power analysis was conducted for a single, two-group between-subjects factor, and a single within-subjects factor assessed over two time points. For this design, 68 participants (34 per group) achieves a power of 0.95 for the within-subjects main effect at an effect size of 0.22 ; and a power of 0.95 for the interaction effect at an effect size of 0.25 .

\subsection{Statistical Analysis}

Continuous variables are presented with mean and standard deviation (SD) and/or with median and interquartile range (IQR). Quantitative variables are presented with absolute and relative frequencies. For the comparison of proportions, chi-square and Fisher's exact tests were used. For the comparison of study variables between the placebo and antioxidant group the Student's $t$-test was computed. Differences in changes of tinnitus parameters, antioxidant parameters, minerals, and vitamins during the follow up period between the two study groups were evaluated using repeated measurements analysis of variance (ANOVA). Variables that had skewed distribution were $\log$-transformed for the analysis of variance. All $p$-values reported are two-tailed. Statistical significance was set at 0.05 and analyses were conducted using SPSS statistical software (version 22.0) (IBM, Armonk, NY, USA).

\section{Results}

Seventy patients with tinnitus met the criteria for recruitment. Out of the 70 patients, 35 were randomized to the antioxidant group and 35 to the placebo. One patient from the antioxidant group and 2 patients from the placebo group discontinued the intervention due to an unscheduled surgery. Moreover, four patients from the placebo group were lost and unable to contact during the follow-up. Sample consisted of 63 patients (29 in the placebo group and 34 in the antioxidant group). No adverse events were mentioned in either of the two groups. Patient compliance was good. Average missed tablets (days) in antioxidant and placebo group were four and five, respectively.

Demographic, clinical, biochemical, and anthropometric characteristics for both groups are presented in Supplementary Material, Table S1. The mean age was 59.2 years (SD $=13.5$ years) for the placebo group and 56.5 years ( $\mathrm{SD}=12.4$ years) for the antioxidant group $(p=0.416)$. Both groups were similar in terms of sex, education, marital status, and smoking habits. Moreover, there were no differences in BMI, waist and hip circumferences and biochemical blood profile. Scores on HADS and CES-D scales along with physical activity levels were also similar for the placebo and antioxidant group (Supplementary Material, Table S1). Table 1 presents the descriptive characteristics of tinnitus and classification of hearing. Tinnitus duration and severity, family history of tinnitus, and hearing loss, as well as the number of previous therapies, the age of tinnitus onset and the presence of normal hearing and hearing loss were similar in the placebo and antioxidant group. 
Table 1. Descriptive characteristics of tinnitus and classification of hearing. The results are given as $N$ (\%) of the total number.

\begin{tabular}{|c|c|c|c|}
\hline & Placebo Group & Antioxidant Group & \multirow{2}{*}{$p$} \\
\hline & $N(\%)$ & $N(\%)$ & \\
\hline \multicolumn{4}{|l|}{ Tinnitus duration (years) } \\
\hline$<1$ & $3(10.3)$ & $3(8.8)$ & \multirow{6}{*}{$0.547^{++}$} \\
\hline $1-2$ & $4(13.8)$ & $9(26.5)$ & \\
\hline $2-3$ & $3(10.3)$ & $5(14.7)$ & \\
\hline $3-5$ & $9(31)$ & $6(17.6)$ & \\
\hline $5-10$ & $2(6.9)$ & $5(14.7)$ & \\
\hline$>10$ & $8(27.6)$ & $6(17.6)$ & \\
\hline \multicolumn{4}{|l|}{ Tinnitus onset } \\
\hline Gradually & $14(48.3)$ & $15(44.1)$ & \multirow{2}{*}{$0.741^{+}$} \\
\hline Abruptly & $15(51.7)$ & $19(55.9)$ & \\
\hline Perceived all day & $22(75.9)$ & $24(70.6)$ & $0.638^{+}$ \\
\hline \multicolumn{4}{|l|}{ Site of the tinnitus } \\
\hline Right ear & $3(10.3)$ & $3(8.8)$ & \multirow{4}{*}{$0.603^{++}$} \\
\hline Left ear & $12(41.4)$ & $9(26.5)$ & \\
\hline Both ears & $13(44.8)$ & $20(58.8)$ & \\
\hline Inside the head & $1(3.4)$ & $2(5.9)$ & \\
\hline History of exposure to noise & $12(41.4)$ & $18(52.9)$ & $0.360^{+}$ \\
\hline Stable loudness all the days & $14(48.3)$ & $17(50)$ & $0.891^{+}$ \\
\hline \multicolumn{4}{|l|}{ Description of tinnitus } \\
\hline Whistle & $14(48.3)$ & $18(52.9)$ & \\
\hline Clatter & $0(0)$ & $2(5.9)$ & \\
\hline Cicadas' noise & $8(27.6)$ & $7(20.6)$ & \\
\hline Blow & $2(6.9)$ & $3(8.8)$ & $0.493^{++}$ \\
\hline Buzzing & $3(10.3)$ & $2(5.9)$ & \\
\hline Other & $2(6.9)$ & $0(0)$ & \\
\hline Bees' noise & $0(0)$ & $2(5.9)$ & \\
\hline \multicolumn{4}{|l|}{ Previous therapies } \\
\hline 0 & $11(37.9)$ & $21(61.8)$ & $0.063^{++}$ \\
\hline 1 & $15(51.7)$ & $8(23.5)$ & \\
\hline 2 & $1(3.4)$ & $4(11.8)$ & \\
\hline 3 & $2(6.9)$ & $1(2.9)$ & \\
\hline \multicolumn{4}{|l|}{ Tinnitus severity } \\
\hline THI, mean (SD) & $40.6(27.7)$ & $31.6(19.3)$ & $0.139 \ddagger$ \\
\hline Tinnitus loudness (db), mean (SD) & $47.1(20.5)$ & $45(15.3)$ & $0.649 \ddagger$ \\
\hline Tinnitus frequency (Hz), mean (SD) & $4431(3078.3)$ & $5562.5(3027.7)$ & $0.147 \ddagger$ \\
\hline MML(db), mean (SD) & $49.3(22.5)$ & $57.9(18.9)$ & $0.110 \ddagger$ \\
\hline Age of tinnitus onset (years), mean (SD) & $54(14.3)$ & $48.2(15.7)$ & $0.138 \ddagger$ \\
\hline Family history of hearing loss & $7(25)$ & $5(14.7)$ & $0.307^{+}$ \\
\hline Family history of tinnitus & $5(17.9)$ & $6(17.6)$ & $1.000^{++}$ \\
\hline \multicolumn{4}{|l|}{ Classification of hearing } \\
\hline $\begin{array}{l}\text { Normal hearing in conventional and } \\
\text { EHF audiometry }\end{array}$ & $10(35.7)$ & $16(47.1)$ & \\
\hline $\begin{array}{l}\text { Mild sensorineural hearing loss in } \\
\text { conventional audiometry }\end{array}$ & $14(50)$ & $13(38.2)$ & $0.651^{++}$ \\
\hline $\begin{array}{l}\text { Moderate sensorineural hearing loss in } \\
\text { conventional audiometry }\end{array}$ & $4(14.3)$ & $5(14.7)$ & \\
\hline $\begin{array}{l}\text { High-frequency sensorineural hearing loss in } \\
\text { EHF audiometry }\end{array}$ & $11(37.9)$ & $9(26.5)$ & \\
\hline
\end{tabular}

${ }^{+}$Pearson's chi-square test; ${ }^{++}$Fisher's exact test; ${ }^{\ddagger}$ Student's $t$-test. THI: Tinnitus Handicap Inventory questionnaire; EHF: extended high frequency. 
Additionally, the two groups were similar as far as the dietary habits are concerned. There were no differences in baseline total energy and macronutrient intake, as well as adherence to the Mediterranean diet assessed by MedDietScore and the frequency of consumption of herbal beverages, chocolate, coffee, and wine as presented in Supplementary Material, Table S2.

The anthropometric and biochemical parameters before and after the intervention are presented in Supplementary Material, Tables S3 and S4. BMI, waist and hip circumferences remained unchanged in both groups after intervention. Moreover, biochemical parameters did not change, apart from LDL, which increased significantly in the antioxidant group. No changes were also reported for the total energy and macro- and micronutrient dietary intake after intervention for both groups (Supplementary Material, Table S5).

The changes for tinnitus loudness, tinnitus frequency and Minimum Masking Level (MML) for both groups after intervention are presented in Table 2. Loudness and MML significantly decreased from baseline to post measure $(p<0.001)$ only in the antioxidant group and the overall change was different between the two groups as indicated from the significant interaction effect of the analysis $(p<0.001)$. Tinnitus frequency did not significantly change in any of the two groups.

Results from the tinnitus questionnaires before and after the intervention revealed that scores of THI, VAS, TFI-Relaxation (TFI-R), and TFI-Emotions (TFI-E) had a significant reduction in the antioxidant group, while no change was recorded in the placebo group (Table 3). A significant interaction effect of group with time indicated a significant treatment difference for THI, TFI-R, and TFI-E (Table 3). Figures 1-4 present the median values for tinnitus loudness, tinnitus frequency, MML, and THI accordingly, displayed as box plots for each group.

To assess if tinnitus duration had any effect on the outcomes, placebo and antioxidant groups were divided in two subgroups according to tinnitus duration. There were no differences in tinnitus loudness, tinnitus frequency, MML and THI between patients with tinnitus duration lower and higher than 10 years at baseline and at follow-up in placebo (Table 4) and antioxidant group (Table 5).

As far as serum concentrations of biomarkers of oxidative stress are concerned (Table 6), serum TAC was decreased significantly in both groups, while SOD and oxLDL did not change in either of the two groups. Differences between the groups in changes in serum TAC, SOD and oxLDL postintervention were insignificant. 
Table 2. Tinnitus loudness, frequency, and minimum masking level (MML) at baseline and at follow-up.

\begin{tabular}{|c|c|c|c|c|c|c|c|c|}
\hline & & \multicolumn{2}{|c|}{ Pre } & \multicolumn{2}{|c|}{ Post } & \multirow{2}{*}{$\begin{array}{c}\text { Change } \\
\text { Mean (SD) }\end{array}$} & \multirow{2}{*}{$p^{1}$} & \multirow{2}{*}{$p^{2}$} \\
\hline & & Mean (SD) & Median (IQR) & Mean (SD) & Median (IQR) & & & \\
\hline \multirow{2}{*}{ Tinnitus loudness $(\mathrm{db})$} & Placebo & $47.1(20.5)$ & $50(30 ; 60)$ & $40.4(15.5)$ & $40(30 ; 50)$ & $-6.7(8.8)$ & 0.168 & \multirow{2}{*}{$<0.001$} \\
\hline & Antioxidant & 45 (15.3) & $40(35 ; 55)$ & $30.8(11.2)$ & $27.5(25 ; 35)$ & $-14.2(12.7)$ & $<0.001$ & \\
\hline \multirow{2}{*}{ Tinnitus frequency $(\mathrm{hz})$} & Placebo & $4431(3078.3)$ & $6000(1000 ; 8000)$ & $4240(2932.6)$ & $4000(1500 ; 6000)$ & $-191(1401.3)$ & 0.303 & \multirow[b]{2}{*}{0.082} \\
\hline & Antioxidant & $5562.5(3027.7)$ & $6000(4000 ; 8000)$ & $5222.7(2982.1)$ & $6000(2500 ; 8000)$ & $-339.8(1565.8)$ & 0.216 & \\
\hline \multirow{2}{*}{ MML (db) } & Placebo & $49.3(22.5)$ & $52.5(30 ; 70)$ & $47.7(21)$ & $47.5(32.5 ; 65)$ & $-1.6(7.4)$ & 0.989 & \multirow{2}{*}{$<0.001$} \\
\hline & Antioxidant & $57.9(18.9)$ & $60(40 ; 75)$ & $43.4(16.5)$ & $40(30 ; 60)$ & $-14.5(14.3)$ & $<0.001$ & \\
\hline
\end{tabular}

${ }^{1} p$-value for the time effect (using logarithmic transformations); ${ }^{2} p$-value from repeated measurements ANOVA. The effects reported include differences between the groups in the degree of change (using logarithmic transformations). 
Table 3. Tinnitus questionnaires' scores at baseline and at follow-up.

\begin{tabular}{|c|c|c|c|c|c|c|c|c|}
\hline & & \multicolumn{2}{|c|}{ Pre } & \multicolumn{2}{|c|}{ Post } & \multirow{2}{*}{$\begin{array}{c}\text { Change } \\
\text { Mean (SD) }\end{array}$} & \multirow{2}{*}{$p^{1}$} & \multirow{2}{*}{$p^{2}$} \\
\hline & & Mean (SD) & Median (IQR) & Mean (SD) & Median (IQR) & & & \\
\hline \multirow{2}{*}{ THI } & Placebo & $40.6(27.7)$ & $30(16 ; 74)$ & $42.8(24.5)$ & $36(26 ; 66)$ & $2.2(11.5)$ & 0.607 & \multirow{2}{*}{0.015} \\
\hline & Antioxidant & $31.6(19.3)$ & $33(16 ; 44)$ & $25.5(18)$ & $21(11 ; 36)$ & $-6.1(11.7)$ & 0.002 & \\
\hline \multirow[b]{2}{*}{ VAS } & Placebo & $5.13(2.81)$ & $5(3.75 ; 7.25)$ & $4.86(2.53)$ & $4.5(3.25 ; 6.6)$ & $-0.3(2.11)$ & 0.767 & \multirow[b]{2}{*}{0.147} \\
\hline & Antioxidant & $3.66(2.49)$ & $3.38(1.25 ; 5.75)$ & $2.88(2.37)$ & $2.38(0.75 ; 4.63)$ & $-0.78(1.4)$ & 0.013 & \\
\hline \multirow{2}{*}{ TFI } & Placebo & $37.9(19.7)$ & $32(22.8 ; 52)$ & $41(22.3)$ & $32.8(27.2 ; 57.6)$ & $3.1(10.3)$ & 0.950 & \multirow[b]{2}{*}{0.410} \\
\hline & Antioxidant & $30.4(20)$ & $29.2(11.4 ; 47)$ & $28.6(20.5)$ & $21.2(13.6 ; 49.6)$ & $-1.8(16.1)$ & 0.129 & \\
\hline \multirow[b]{2}{*}{ TFI-I } & Placebo & $56.9(26.4)$ & $60(31.7 ; 75)$ & 62.7 (26.6) & $70(45 ; 83.3)$ & $5.7(17.2)$ & 0.518 & \multirow{2}{*}{0.666} \\
\hline & Antioxidant & $48.3(27.3)$ & $45(23.3 ; 71.7)$ & $48.3(27.8)$ & $43.3(20 ; 76.7)$ & $0.1(20.5)$ & 0.873 & \\
\hline \multirow{2}{*}{ TFI-SC } & Placebo & $61.9(27)$ & $56.7(48.3 ; 86.7)$ & $65.9(21.8)$ & $60(56.7 ; 76.7)$ & $4(10.9)$ & 0.964 & \multirow{2}{*}{0.376} \\
\hline & Antioxidant & $44.2(29.3)$ & $40(20 ; 66.7)$ & 39.9 (27.7) & $40(20 ; 56.7)$ & $-4.3(21.3)$ & 0.120 & \\
\hline \multirow[b]{2}{*}{ TFI-C } & Placebo & $31(31.4)$ & $30(0 ; 45)$ & $22.1(26.4)$ & $13.3(0 ; 30)$ & $-8.9(29.2)$ & 0.294 & \multirow[b]{2}{*}{0.939} \\
\hline & Antioxidant & $31.6(28.1)$ & $23.3(8.3 ; 51.7)$ & $27.7(26.9)$ & $13.3(3.3 ; 60)$ & $-3.8(23.4)$ & 0.187 & \\
\hline \multirow{2}{*}{ TFI-SL } & Placebo & $33.6(32.7)$ & $26.7(3.3 ; 61.7)$ & 36.9 (32.7) & $23.3(10 ; 66.7)$ & $3.3(6.9)$ & 0.720 & \multirow{2}{*}{0.236} \\
\hline & Antioxidant & $23.1(26.9)$ & $13.3(0 ; 45)$ & $23(30.3)$ & $10(0 ; 46)$ & $-0.1(24.6)$ & 0.128 & \\
\hline \multirow{2}{*}{ TFI-A } & Placebo & $31.2(32.4)$ & $23.3(0 ; 56.7)$ & $23.5(31.9)$ & $6.7(0 ; 50)$ & $-7.8(11.7)$ & 0.612 & \multirow{2}{*}{0.836} \\
\hline & Antioxidant & $24.2(25.2)$ & $13.3(0 ; 40)$ & $23.9(23.7)$ & $16.7(3.3 ; 36.7)$ & $-0.3(18)$ & 0.726 & \\
\hline \multirow{2}{*}{ TFI-R } & Placebo & $49.3(31.8)$ & $55(18.3 ; 73.3)$ & $60.8(22.7)$ & $66.7(43.3 ; 76.7)$ & $11.5(19.1)$ & 0.189 & \multirow{2}{*}{0.037} \\
\hline & Antioxidant & 34.7 (29.6) & $25(8.3 ; 65)$ & $26.5(26.2)$ & $13.3(3.3 ; 50)$ & $-8.2(22.5)$ & 0.044 & \\
\hline \multirow{2}{*}{ TFI-Q } & Placebo & $27.2(29)$ & $20(0 ; 50)$ & $24.9(29.3)$ & $25(0 ; 37.5)$ & $-2.4(11)$ & 0.842 & \multirow{2}{*}{0.897} \\
\hline & Antioxidant & $14.3(16.2)$ & $10(0 ; 30)$ & $18.1(21.1)$ & $10(0 ; 25)$ & $3.8(17.7)$ & 0.957 & \\
\hline \multirow{2}{*}{ TFI-E } & Placebo & $41.2(36.7)$ & $30(10 ; 68.3)$ & $41(36.3)$ & $30(10 ; 73.3)$ & $-0.2(10.8)$ & 0.789 & \multirow{2}{*}{0.042} \\
\hline & Antioxidant & $29.2(26)$ & $20(6.7 ; 50)$ & $23.3(22.6)$ & $20(6.7 ; 40)$ & $-5.8(18.1)$ & 0.006 & \\
\hline
\end{tabular}

${ }^{1} p$-value for the time effect (using logarithmic transformations); ${ }^{2} p$-value from repeated measurements ANOVA. The effects reported include differences between the groups in the degree of change (using logarithmic transformations). THI: Tinnitus Handicap Inventory, VAS: Visual Analogue Scale; TFI: Tinnitus Functional Index. 


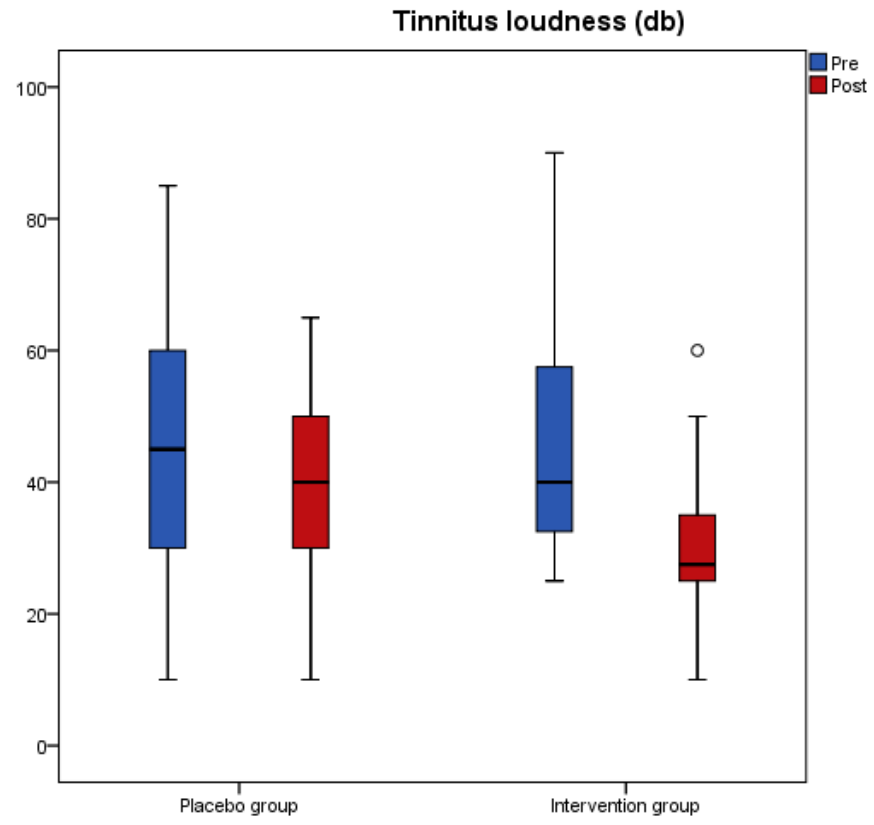

Figure 1. Tinnitus loudness $(\mathrm{db})$ is displayed as box plots for each group at baseline and at follow-up. The line inside the box represents the median and the box portion of the box plot is defined by two lines at the 25 th percentile and 75 th percentile. Circles denote outliers.

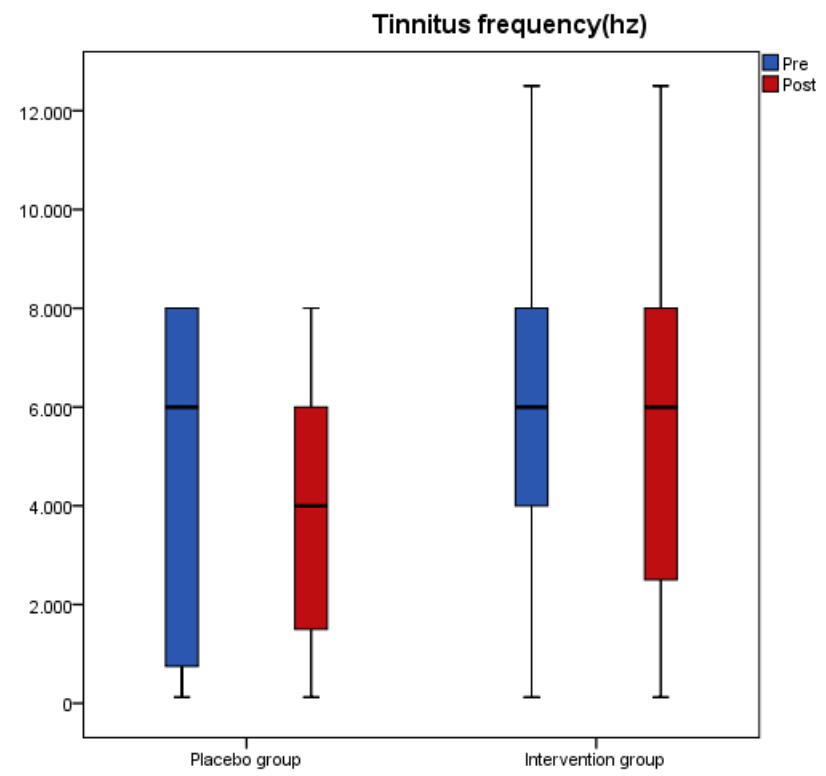

Figure 2. Tinnitus frequency $(\mathrm{Hz})$ is displayed as box plots for each group at baseline and at follow-up. The line inside the box represents the median and the box portion of the box plot is defined by two lines at the 25 th percentile and 75 th percentile. 
MML (db)

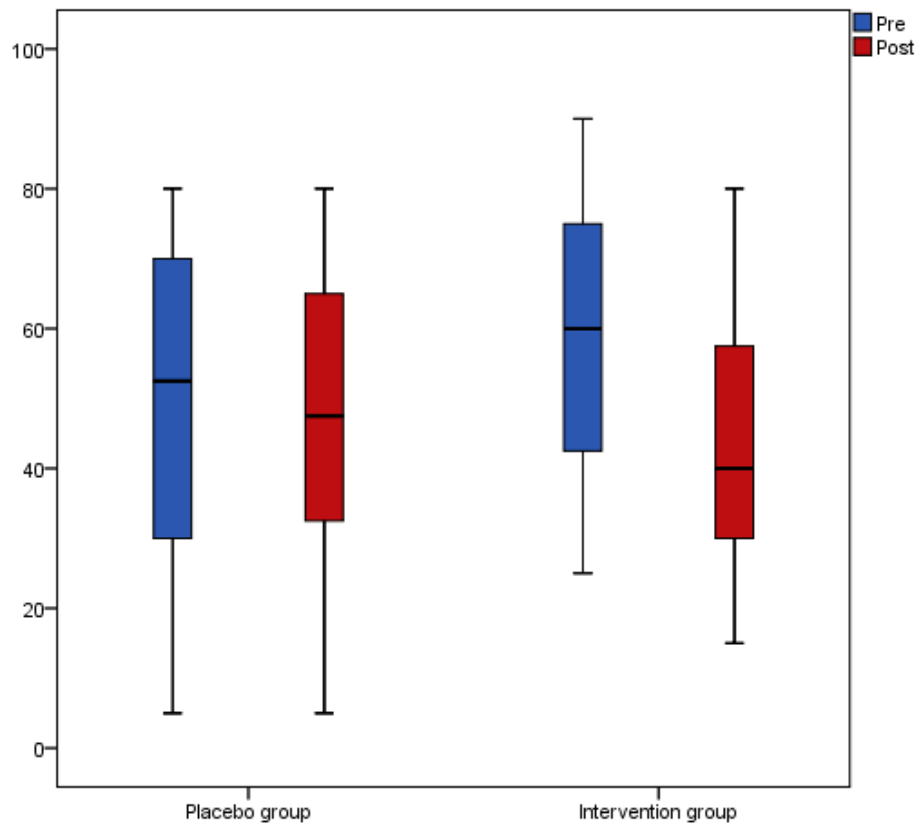

Figure 3. MML $(\mathrm{db})$ is displayed as box plots for each group at baseline and at follow-up. The line inside the box represents the median and the box portion of the box plot is defined by two lines at the 25th percentile and 75 th percentile.

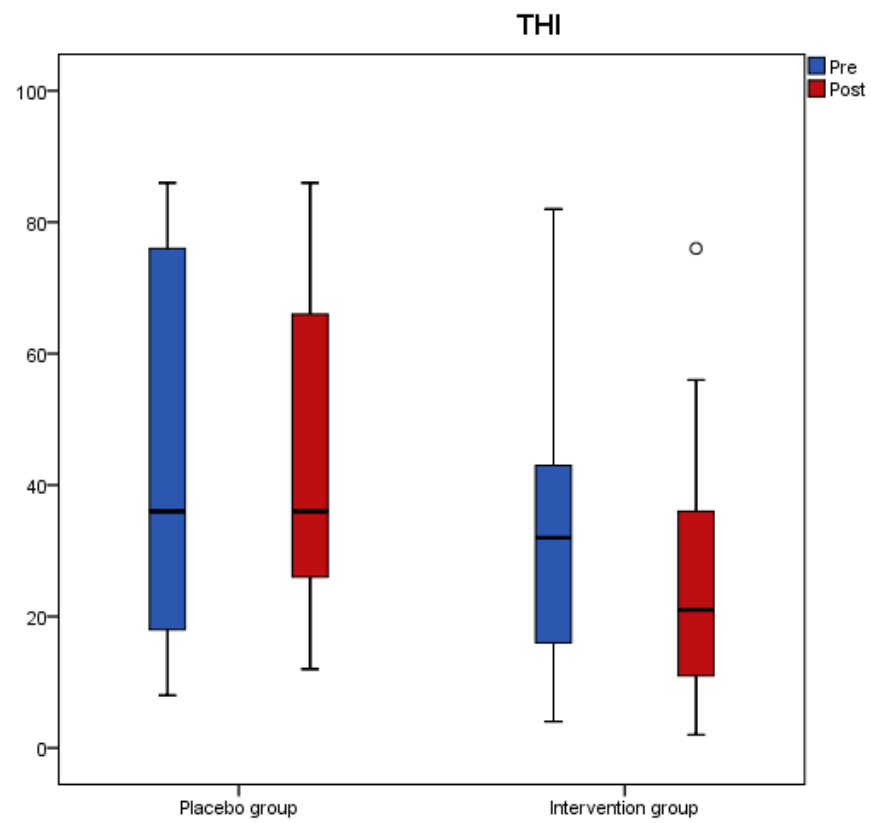

Figure 4. THI is displayed as box plots for each group at baseline and at follow-up. The line inside the box represents the median and the box portion of the box plot is defined by two lines at the 25th percentile and 75th percentile. Circles denote outliers. 
Table 4. Tinnitus loudness, frequency, MML, and THI in patients with tinnitus duration of $<10$ years and $>10$ years at baseline and at follow-up in placebo group.

\begin{tabular}{|c|c|c|c|c|c|}
\hline & \multicolumn{4}{|c|}{ Tinnitus Duration } & \multirow{3}{*}{ P Mann-Whitney Tes } \\
\hline & \multicolumn{2}{|c|}{$<10$ Years } & \multicolumn{2}{|c|}{$>10$ Years } & \\
\hline & Mean (SD) & Median (IQR) & Mean (SD) & Median (IQR) & \\
\hline Tinnitus loudness (db) (pre) & $46.9(22.8)$ & $50(30 ; 60)$ & $47.5(13.9)$ & $47.5(35 ; 60)$ & 0.769 \\
\hline Tinnitus loudness (db) (post) & $39.7(16.3)$ & $42.5(25 ; 50)$ & $42.1(14.1)$ & $35(30 ; 60)$ & 0.784 \\
\hline Tinnitus frequency (Hz) (pre) & $4011.9(3230)$ & $4000(750 ; 8000)$ & $5531.3(2487.2)$ & $6000(5000 ; 7000)$ & 0.345 \\
\hline Tinnitus frequency (Hz) (post) & $3875(3082.2)$ & $4000(1000 ; 8000)$ & $5178.6(2461)$ & $6000(4000 ; 6000)$ & 0.373 \\
\hline MML (db) (pre) & $47.5(24.3)$ & $45(30 ; 70)$ & $53.8(17.7)$ & $55(42.5 ; 65)$ & 0.557 \\
\hline MML (db) (post) & $45.3(22.7)$ & $45(25 ; 65)$ & $53.6(16.3)$ & $60(35 ; 65)$ & 0.426 \\
\hline THI (pre) & $42(30.5)$ & $30(14 ; 76)$ & $36.8(19.3)$ & $31(22 ; 48)$ & 0.961 \\
\hline THI (post) & $46.1(27.5)$ & $46(16 ; 76)$ & $34.3(11.7)$ & $30(26 ; 50)$ & 0.467 \\
\hline
\end{tabular}

Table 5. Tinnitus loudness, frequency, MML and scores in THI in patients with tinnitus duration of $<10$ years and $>10$ years at baseline and at follow-up in antioxidant group.

\begin{tabular}{|c|c|c|c|c|c|}
\hline & \multicolumn{4}{|c|}{ Tinnitus Duration } & \multirow{3}{*}{ P Mann-Whitney Tes } \\
\hline & \multicolumn{2}{|c|}{$<10$ Years } & \multicolumn{2}{|c|}{$>10$ Years } & \\
\hline & Mean (SD) & Median (IQR) & Mean (SD) & Median (IQR) & \\
\hline Tinnitus loudness (db) (pre) & $43(13.7)$ & $40(30 ; 52.5)$ & $54.2(20.1)$ & $45(40 ; 65)$ & 0.199 \\
\hline Tinnitus loudness (db) (post) & $30.6(11.5)$ & $27.5(25 ; 35)$ & $31.7(10.8)$ & $30(25 ; 35)$ & 0.825 \\
\hline Tinnitus frequency $(\mathrm{Hz})$ (pre) & $5183(3187.5)$ & $4500(2000 ; 8000)$ & $7333.3(1032.8)$ & $8000(6000 ; 8000)$ & 0.080 \\
\hline Tinnitus frequency $(\mathrm{Hz})$ (post) & $4889.4(3142.9)$ & $5000(2000 ; 8000)$ & $6666.7(1633)$ & $7000(6000 ; 8000)$ & 0.152 \\
\hline MML (db) (pre) & $56.9(18.7)$ & $55(40 ; 75)$ & $62.5(21.2)$ & $65(60 ; 70)$ & 0.574 \\
\hline MML (db) (post) & $43.2(16.4)$ & $40(30 ; 55)$ & $44.2(18.6)$ & $40(30 ; 60)$ & 1.000 \\
\hline THI (pre) & $30.4(17.9)$ & $29(16 ; 43)$ & $37.3(26.3)$ & $37(20 ; 44)$ & 0.586 \\
\hline THI (post) & $23.5(15.9)$ & $20(10 ; 36)$ & $34(25.4)$ & $30(12 ; 48)$ & 0.371 \\
\hline
\end{tabular}


Table 6. Oxidative stress biomarkers at baseline and at follow-up.

\begin{tabular}{|c|c|c|c|c|c|c|c|c|}
\hline & & \multicolumn{2}{|c|}{ Pre } & \multicolumn{2}{|c|}{ Post } & \multirow{2}{*}{$\begin{array}{c}\text { Change } \\
\text { Mean (SD) }\end{array}$} & \multirow{2}{*}{$p^{1}$} & \multirow{2}{*}{$p^{2}$} \\
\hline & & Mean (SD) & Median (IQR) & Mean (SD) & Median (IQR) & & & \\
\hline \multirow{2}{*}{ serum TAC $(\mathrm{m} \mathrm{M})$} & Placebo & $5.5(1.5)$ & $5.2(4.5 ; 7)$ & $3.9(2.9)$ & $2.4(1.4 ; 6.6)$ & $-1.7(3.5)$ & 0.002 & \multirow{2}{*}{0.420} \\
\hline & Antioxidant & $6.3(1.9)$ & $6.1(5.3 ; 7.2)$ & $5.1(2.7)$ & $5.5(3.5 ; 7.2)$ & $-1.1(3.8)$ & 0.019 & \\
\hline \multirow{2}{*}{$\mathrm{SOD}(\mathrm{U} / \mathrm{mL})$} & Placebo & $3.2(2)$ & $2.5(2.2 ; 2.9)$ & $3.1(1.8)$ & $2.6(2.2 ; 3.2)$ & $-0.1(1.4)$ & 0.792 & \multirow[b]{2}{*}{0.154} \\
\hline & Antioxidant & $4(2.5)$ & $3.3(2.6 ; 4.4)$ & $3(1.6)$ & $2.6(2 ; 3.3)$ & $-1(2.3)$ & 0.065 & \\
\hline \multirow{2}{*}{ ox.LDL (ng/mL) } & Placebo & $12.1(23.2)$ & $7(2 ; 10.9)$ & $10.4(8.5)$ & $9(5.1 ; 11.4)$ & $-1.7(7.9)$ & 0.062 & \multirow{2}{*}{0.232} \\
\hline & Antioxidant & $25(50.7)$ & $7.7(3.8 ; 15.8)$ & $18.7(37.6)$ & $8.8(7.8 ; 9.6)$ & $-6.3(27.9)$ & 0.399 & \\
\hline
\end{tabular}

${ }_{1} p$-value for the time effect; ${ }^{2} p$-value from repeated measurements ANOVA. The effects reported include differences between the groups in the degree of change (using logarithmic transformations). 
Figures 5 and 6 present pure-tone thresholds in the frequency range from 250 to $12,000 \mathrm{~Hz}$ (dB $\mathrm{HL}$ ) as box plots for each frequency at baseline and at follow-up in the placebo and antioxidant group accordingly. The degree of change in the PTA thresholds at the frequencies of $250 \mathrm{~Hz}, 2000 \mathrm{~Hz}, 4000 \mathrm{~Hz}$, $10,000 \mathrm{~Hz}$, and $12,000 \mathrm{~Hz}$ differed significantly between the two groups. Specifically, at the frequencies of $250 \mathrm{~Hz}, 500 \mathrm{~Hz}, 1000 \mathrm{~Hz}, 2000 \mathrm{~Hz}$, and $6000 \mathrm{~Hz}$ there was a significant decrease in the auditory threshold only in the antioxidant group whereas in the placebo group there was no significant change post intervention. At the frequency of $10,000 \mathrm{~Hz}$ there was a significant increase only in the placebo group while in the antioxidant group there was no significant change after the intervention. At the frequencies of $4000 \mathrm{~Hz}$ and $12,000 \mathrm{~Hz}$ there was a significant decrease in the antioxidant group and a significant increase in the placebo group.

As a measure of compliance, blood status of vitamins and minerals was evaluated and results are presented in Table 7. Vitamin D, folate, vitamin B2, vitamin B1, and vitamin B6 levels increased significantly in the antioxidant group postintervention, whereas iron, magnesium, zinc, selenium, vitamin B12, vitamin E, and vitamin C levels remained unchanged. The estimated treatment difference was significant for folic acid as indicated from the interaction effect of the analysis $(p=0.049)$. In the placebo group, vitamin and mineral levels did not change post-intervention.

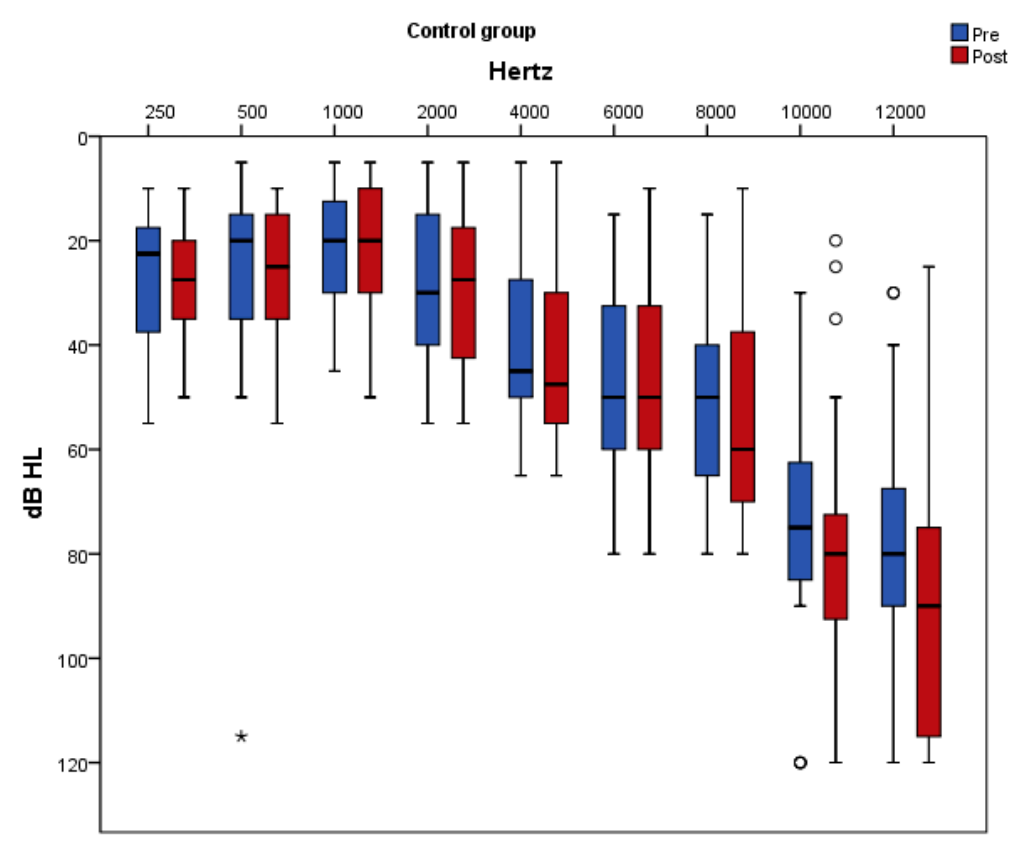

Figure 5. Pure-tone thresholds in the frequency range from 250 to $12,000 \mathrm{~Hz}$ (dB HL) are displayed as box plots for each frequency in the placebo group at baseline and at follow-up. The line inside the box represents the median and the box portion of the box plot is defined by two lines at the 25th percentile and 75th percentile. Circles denote outliers and asterisks denote extreme values. 


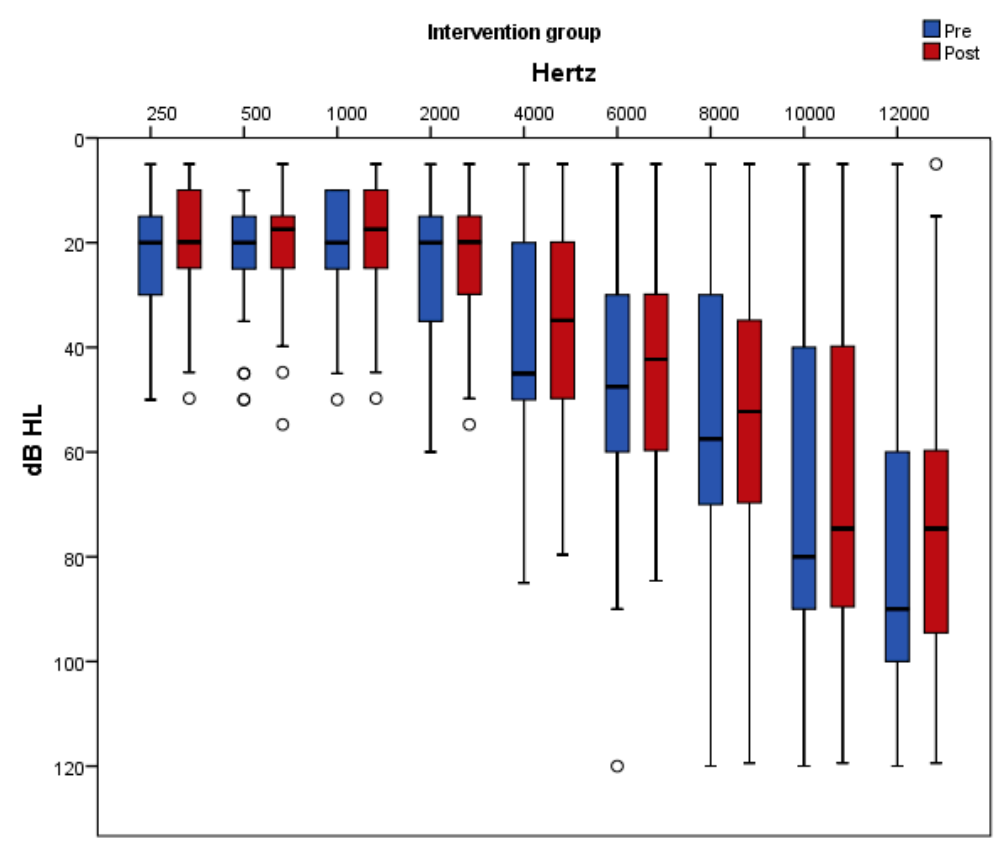

Figure 6. Pure-tone thresholds in the frequency range from 250 to $12,000 \mathrm{~Hz}$ (dB HL) are displayed as box plots for each frequency in the antioxidant group at baseline and at follow-up. The line inside the box represents the median and the box portion of the box plot is defined by two lines at the 25th percentile and 75th percentile. Circles denote outliers.

Table 7. Blood status of vitamins and minerals at baseline and at follow-up. Values are expressed as the mean \pm SD.

\begin{tabular}{|c|c|c|c|c|c|c|}
\hline & & Pre & Post & Change & \multirow{2}{*}{$p^{1}$} & \multirow{2}{*}{$p^{2}$} \\
\hline & & Mean (SD) & Mean (SD) & Mean (SD) & & \\
\hline \multirow{2}{*}{$\begin{array}{c}\text { Vitamin D } \\
(\mathrm{ng} / \mathrm{mL})\end{array}$} & Placebo & $0.32(0.23)$ & $0.28(0.13)$ & $-0.05(0.16)$ & 0.657 & \multirow{2}{*}{0.079} \\
\hline & Antioxidant & $0.32(0.22)$ & $0.4(0.42)$ & $0.08(0.36)$ & 0.032 & \\
\hline \multirow{2}{*}{$\begin{array}{l}\text { Magnesium } \\
(\mathrm{mg} / \mathrm{dL})\end{array}$} & Placebo & $2.06(0.11)$ & $2.03(0.1)$ & $-0.03(0.16)$ & 0.834 & \multirow{2}{*}{0.355} \\
\hline & Antioxidant & $2.01(0.12)$ & $2.07(0.16)$ & $0.06(0.17)$ & 0.066 & \\
\hline \multirow{2}{*}{$\mathrm{Zn}(\mu \mathrm{g} / \mathrm{dL})$} & Placebo & $105.8(14.8)$ & $98.6(11)$ & $-7.1(12.7)$ & 0.128 & \multirow{2}{*}{0.148} \\
\hline & Antioxidant & $111.6(15.4)$ & $112(15.7)$ & $0.5(23.4)$ & 0.777 & \\
\hline \multirow{2}{*}{$\mathrm{B} 12(\mathrm{pg} / \mathrm{mL})$} & Placebo & $465.3(330.6)$ & $358.3(167.8)$ & $-106.9(378.2)$ & 0.080 & \multirow{2}{*}{0.095} \\
\hline & Antioxidant & $359.8(130.3)$ & $411.9(98.5)$ & $52.1(110.5)$ & 0.657 & \\
\hline \multirow{2}{*}{ Folate (ng/mL) } & Placebo & $8.16(4.99)$ & $6.45(2.14)$ & $-1.71(1.13)$ & 0.463 & \multirow{2}{*}{0.049} \\
\hline & Antioxidant & $8.65(5.21)$ & $11.31(5.41)$ & $2.66(4.29)$ & 0.001 & \\
\hline \multirow{2}{*}{$\mathrm{Fe}(\mu \mathrm{g} / \mathrm{dL})$} & Placebo & $128.2(42.1)$ & $118.5(62.5)$ & $-9.6(65.6)$ & 0.963 & \multirow{2}{*}{0.309} \\
\hline & Antioxidant & $117.8(36.2)$ & $104.7(41)$ & $-13.1(36)$ & 0.134 & \\
\hline \multirow{2}{*}{ Selenium ( $\mu \mathrm{g} / \mathrm{L})$} & Placebo & $76.5(11.8)$ & $68.2(7)$ & $-8.3(15.4)$ & 0.080 & \multirow{2}{*}{0.095} \\
\hline & Antioxidant & $78.4(9.5)$ & $80.1(11.3)$ & $1.7(13.4)$ & 0.730 & \\
\hline \multirow{2}{*}{ Vitamin E (mg/L) } & Placebo & $12.09(0.94)$ & $11.68(1.04)$ & $-0.41(0.79)$ & 0.908 & \multirow{2}{*}{0.798} \\
\hline & Antioxidant & $11.42(1.16)$ & $11.92(1.15)$ & $0.5(1.56)$ & 0.411 & \\
\hline \multirow{2}{*}{ Vitamin $C(\mu \mathrm{g} / \mathrm{L})$} & Placebo & $6.73(1.65)$ & $7.03(2.73)$ & $0.31(3.65)$ & 0.324 & \multirow{2}{*}{0.530} \\
\hline & Antioxidant & $7.25(1.82)$ & $7.73(2.41)$ & $0.48(3.22)$ & 0.509 & \\
\hline \multirow{2}{*}{ Vitamin B2 $(\mu \mathrm{g} / \mathrm{L})$} & Placebo & $220(22.4)$ & $223.6(18)$ & $3.6(11.1)$ & 0.918 & \multirow{2}{*}{0.326} \\
\hline & Antioxidant & $221.7(25.2)$ & $238.4(26.6)$ & $16.7(32.4)$ & 0.039 & \\
\hline \multirow{2}{*}{ Vitamin B1 $(\mu \mathrm{g} / \mathrm{L})$} & Placebo & $55(12.4)$ & $56.8(14.8)$ & $1.8(27.2)$ & 0.757 & \multirow{2}{*}{0.468} \\
\hline & Antioxidant & $50.4(11.1)$ & $61.5(13.5)$ & $11.1(17.7)$ & 0.023 & \\
\hline \multirow{2}{*}{ Vitamin B6 $(\mu \mathrm{g} / \mathrm{L})$} & Placebo & $21.5(3.6)$ & $22.8(5.6)$ & $1.3(6)$ & 0.911 & \multirow{2}{*}{0.463} \\
\hline & Antioxidant & $24.2(17.2)$ & $35.6(12.9)$ & $11.4(19.9)$ & 0.050 & \\
\hline
\end{tabular}

${ }^{1} p$-value for the time effect; ${ }^{2} p$-value from repeated measurements ANOVA. The effects reported include differences between the groups in the degree of change (using logarithmic transformations). 


\section{Discussion}

Herein, the efficacy of antioxidant supplementation with vitamins, minerals and phytochemicals combined with ALA on tinnitus parameters and subjective discomfort has been investigated. Furthermore, the effect of antioxidant supplementation on biomarkers of oxidative stress has been assessed.

Given that tinnitus is a symptom that has multiple dimensions, psychoacoustic measures of tinnitus (loudness, frequency, and MML) together with questionnaires assessing the tinnitus subjective discomfort (THI, TFI, and VAS-annoyance scale) were applied in the present study in order to assess the efficacy of antioxidant supplementation. This was done in accordance with the Consensus for tinnitus patient assessment and treatment outcome measurement [43]. Separate assessment of psychoacoustic features of the tinnitus and tinnitus related distress in everyday life is highly recommended, since they have a weak correlation with each other [44,45]. Our findings showed that tinnitus loudness, MML and scores in THI, VAS, TFI-relaxation, and TFI-emotions decreased significantly only in the antioxidant group, with the overall changes being significantly different between the two groups post-intervention. This means that antioxidant supplementation was effective in improving tinnitus' sensory aspects (tinnitus loudness and MML) and in alleviating patients from tinnitus-related distress compared to placebo. The mean reduction in the THI score of 6 points in the antioxidant group, is considered a clinically relevant change [46]. In accordance with present findings, a significant reduction in the VAS scale and tinnitus loudness was reported after an 18-week supplementation with a mix of phospholipids and vitamins [15].

At the same time, this study showed that antioxidant supplementation led to significant improvements of hearing thresholds across all frequencies, with the overall changes being significantly different between the two groups at the frequencies of $250 \mathrm{~Hz}, 2000 \mathrm{~Hz}, 4000 \mathrm{~Hz}, 10,000 \mathrm{~Hz}$, and $12,000 \mathrm{~Hz}$. Improved thresholds at frequencies between $250 \mathrm{~Hz}$ and $8000 \mathrm{~Hz}$ is of high importance, since these are the frequencies used for speech recognition and thus tinnitus patients could benefit from a better understanding of speech and language.

Despite the key role of oxidative stress in the pathogenesis of tinnitus, data on the efficacy of antioxidant supplementation on oxidative stress biomarkers in tinnitus patients are scarce. This study assessed oxidative stress by measuring serum oxLDL. OxLDL, measured in blood using immunological methods (i.e., antibodies), is considered by the European Food Safety Authority (EFSA) as a reliable in vivo marker of oxidative damage with appropriate specificity [47]. Moreover, serum TAC and SOD were measured in order to assess total antioxidant status and endogenous antioxidant activity accordingly. No statistically significant differences were observed in changes in serum TAC, SOD, and oxLDL in the antioxidant group compared to placebo group post-intervention. These results are consistent with other studies which have been done in healthy adults or adults with concomitant diseases (i.e., diabetes, CVD) and have shown that antioxidant supplementation had no effect on ox.LDL [48,49], SOD [50-52], or TAC [51,52]. The absence of any effect of antioxidant supplementation on serum ox. LDL and TAC may be due to the low doses of vitamins C (150 mg) and a-tocopherol (150 IU) in the supplement used. As such, the plasma levels of vitamins $C$ and $E$ in the antioxidant group post-intervention remained unchanged. TAC measures total endogenous and food-derived antioxidants and its values are affected by serum concentrations of vitamins E and C [53]. Moreover, it has been shown that a significant reduction in LDL susceptibility to oxidation could be achieved with a minimum dose of $400 \mathrm{IU} / \mathrm{d}$ of $\alpha$-tocopherol supplementation [54].

Antioxidant supplementation studies in tinnitus are limited. Moreover, in most of them a monotherapy treatment approach has been proposed such as zinc $[16,55,56]$, with no benefit in tinnitus. On the contrary, our hypothesis was that an antioxidant combination might be more effective compared with single nutrients, since various antioxidants have a synergistic/complementary activity [57]. A-lipoic acid was used hereby, at a dose of $600 \mathrm{mg}$ daily that has been demonstrated to increase lipoic acid levels in plasma or cells $[58,59]$. Moreover, the standardized grape seed extract (GSE) contained in the multivitamin-multimineral supplement constitutes a rich source of phenolic 
compounds including epicatechin, resveratrol and procyanidin oligomers [60]. To the best of our knowledge, this is the first randomized double-blind placebo-controlled study which used a mixture of vitamins, minerals, phytochemicals and ALA in tinnitus.

The beneficial effect observed on tinnitus in this study is most likely attributed to the protective mechanisms of antioxidants contained in the supplements against ROS-induced cochlear hair cell damage. This has been verified from experiments using animal models, in-vitro assays, or auditory cell lines in cases of ototoxicity, age-related or noise-induced hearing loss. A recent study using cochlea explant culture from mice showed that resveratrol, DL- $\alpha$-lipoic acid and a-tocopherol protected against gentamicin-induced hair cell loss [61]. In animal experiments, vitamins $E$ or $C$ treatment resulted in better auditory sensitivity and less mtDNA deletions with aging [62] and vitamin E or a-lipoic acid attenuated the noise-induced increase of cochlear malondialdehyde [18]. Moreover, a combination of vitamins B1, B2, B6, E, and C was effective in protecting against cisplatin ototoxicity [63] and $\alpha$-lipoic acid inhibited the kanamycin-induced high expression of phosphorylated p38 and phosphorylated JNK, which mediate cochlear hair cell apoptosis [64]. In studies using auditory cell lines, treatment with D- $\alpha$-tocopherol or epicatechin reduced the cisplatin-induced increase of ROS and decreased cellular necrosis and apoptosis $[65,66]$.

Apart from their antioxidant mediated effects, compounds in the supplements used may have acted via additional mechanisms. ALA has been widely researched as a neuroprotectant [67] and vitamin B complex play a key role in the functioning of nerve tissue, cellular metabolism, vascular function, and myelin synthesis [68]. Low levels of Vitamin B12 and folate have been associated with decreased endocochlear potential due to the destruction of the microvasculature of the stria vascularis [69]. Moreover, a diet deficient in folate in animals may lead to impaired cochlear homocysteine metabolism and oxidative stress [70].

Despite the interesting results of this study and the advantage of being randomized and double-blinded, it has some limitations, including the enrollment of patients with high levels of oxidative stress (e.g., smokers, diabetics, elderly), the presence of compounds other than antioxidants in the supplement used and the heterogeneity of participants as far as tinnitus duration and severity, hearing loss, family history and age of tinnitus onset are concerned, shown to influence the response to treatment [71,72]. However, these limitations are compensated by the tight control of participants to ensure their compliance with the protocol, as well as the long follow-up and the adequate sample size of the study.

\section{Conclusions}

Results of this study showed that antioxidant supplementation with vitamins, minerals, phytochemicals and ALA could exhibit favorable effects in tinnitus by reducing the subjective discomfort and tinnitus intensity. However, the effect of this antioxidant supplementation in oxidative stress biomarkers in tinnitus patients needs further investigation.

Supplementary Materials: The following are available online at http://www.mdpi.com/2072-6643/11/12/3037/s1, Table S1: Sample characteristics by study group, Table S2: MedDietScore, antioxidant food consumption frequency and macronutrient intake by study group, Table S3: Anthropometrics at baseline and at follow up. Values are expressed as the mean \pm SD, Table S4: Biochemical parameters at baseline and at follow up, Table S5: Macro- and micronutrient intake at baseline and at follow-up.

Author Contributions: Conceptualization, A.I.P. and G.K.; Methodology, I.X. and A.C.K.; Investigation, A.I.P., G.K., and E.T.Z. (Data collection), M.G. (Contribution to laboratory work) and E.T.Z. (Participation in patient recruitment); Resources, A.I.P.; Writing-Original Draft Preparation, A.I.P., E.T.Z., P.P., G.S.K., E.K.; Writing-Review and Editing, A.C.K. and A.I.P.; Visualization, A.C.K.; Supervision, A.C.K. and I.X.; Project Administration, I.X.

Funding: This research received no external funding.

Acknowledgments: All authors have approved the final article. We are grateful to the patients for participating in this study. We are thankful to Lamberts for the kind donation of supplements. We are also thankful to Chara Tzavara for her assistance in statistical analysis.

Conflicts of Interest: The authors declare no conflict of interest. 


\section{Appendix A}

\section{O N S O R T}

TRANSPARENT REPORTING of TRIALS

\section{CONSORT 2010 Flow Diagram}

Excluded $(n=30)$

- Not meeting inclusion criteria $(n=25)$

- Declined to participate $(n=5)$

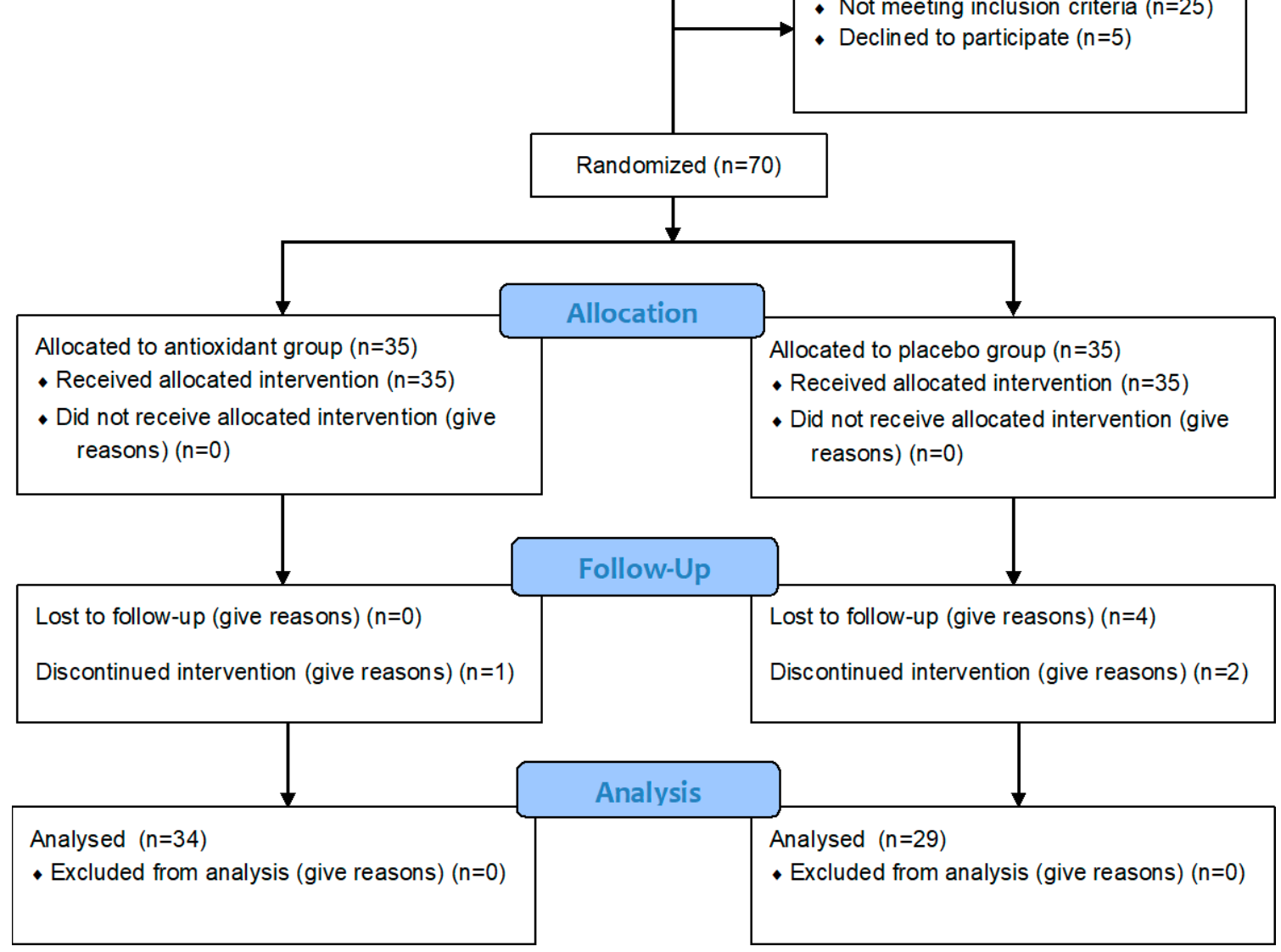




\section{Appendix B}

\begin{tabular}{|c|c|c|c|c|c|}
\hline \multicolumn{6}{|c|}{ Composition of the Multivitamin-Multimineral Supplement (1 Table) } \\
\hline Ingredient & $\begin{array}{l}\text { Amount per } \\
\text { tablet }\end{array}$ & $\%$ RDA & Ingredient & $\begin{array}{l}\text { Amount } \\
\text { per tablet }\end{array}$ & $\%$ RDA \\
\hline Vitamin A (acetate) & $781 \mu g(2600 \mathrm{iu})$ & 98 & Magnesium (as oxide) & $50 \mathrm{mg}$ & 13 \\
\hline Vitamin $D_{3}$ & $10 \mu \mathrm{g}(400 \mathrm{iu})$ & 200 & Zinc (gluconate) & $15 \mathrm{mg}$ & 150 \\
\hline $\begin{array}{l}\text { Vitamin E (dl-alpha } \\
\text { tocopherol acetate) }\end{array}$ & $100 \mathrm{mg}(150 \mathrm{iu})$ & 833 & Copper (gluconate) & $1.2 \mathrm{mg}$ & 120 \\
\hline Vitamin C (Ascorbic acid) & $150 \mathrm{mg}$ & 188 & Manganese (gluconate) & $4 \mathrm{mg}$ & 200 \\
\hline $\begin{array}{l}\text { Thiamine (Vitamin B1) } \\
\text { (mononitrate) }\end{array}$ & $25 \mathrm{mg}$ & 2272 & $\begin{array}{c}\text { Selenium (as } \\
\text { L-Selenomethionine and } \\
\text { sodium selenite) }\end{array}$ & $100 \mu \mathrm{g}$ & 200 \\
\hline Riboflavin (Vitamin B2) & $25 \mathrm{mg}$ & 1786 & Chromium (picolinate) & $200 \mu \mathrm{g}$ & 500 \\
\hline Niacin (Vitamin B3) & $25 \mathrm{mg}$ & 156 & $\begin{array}{l}\text { Molybdenum } \\
\text { (as molybdate) }\end{array}$ & $500 \mu \mathrm{g}$ & 1000 \\
\hline $\begin{array}{c}\text { Pyridoxine (Vitamin B6) } \\
\text { (Pyridoxine Hydrochloride) }\end{array}$ & $10 \mathrm{mg}$ & 714 & Iodine (potassium iodide) & $150 \mu \mathrm{g}$ & 100 \\
\hline Folic acid & $200 \mu \mathrm{g}$ & 100 & Choline (Bitartrate) & $25 \mathrm{mg}$ & \\
\hline Vitamin B12 & $10 \mu \mathrm{g}$ & 400 & Inositol & $25 \mathrm{mg}$ & \\
\hline Biotin & $150 \mu \mathrm{g}$ & 300 & PABA & $25 \mathrm{mg}$ & \\
\hline $\begin{array}{l}\text { Pantothenic acid (Vitamin } \\
\text { B5) (calcium pantothenate) }\end{array}$ & $25 \mathrm{mg}$ & 417 & $\begin{array}{l}\text { Grapeseed extract (GSE) } \\
\text { (Provided by } 1 \mathrm{mg} \text { of } \\
\text { a } 500: 1 \text { extract) }\end{array}$ & $500 \mathrm{mg}$ & \\
\hline Calcium (as phosphate) & $62 \mathrm{mg}$ & 8 & & & \\
\hline Iron (ferrous fumarate) & $14 \mathrm{mg}$ & 100 & & & \\
\hline
\end{tabular}

\section{References}

1. Jastreboff, P.J. Phantom auditory perception (tinnitus): Mechanisms of generation and perception. Neurosci. Res. 1990, 8, 221-254. [CrossRef]

2. Baguley, D.; McFerran, D.; Hall, D. Tinnitus. Lancet 2013, 382, 1600-1607. [CrossRef]

3. Ciorba, A.; Bianchini, C.; Pastore, A.; Mazzoli, M. Pathogenesis of Tinnitus: Any Role for Oxidative Stress? J. Int. Adv. Otol. 2013, 9, 249-254.

4. Poirrier, A.L.; Pincemail, J.; Van Den Ackerveken, P.; Lefebvre, P.P.; Malgrange, B. Oxidative stress in the cochlea: An update. Curr. Med. Chem. 2010, 17, 3591-3604. [CrossRef] [PubMed]

5. Gonzalez-Gonzalez, S. The role of mitochondrial oxidative stress in hearing loss. Neurol. Disord. Ther. 2017, 1. [CrossRef]

6. Sha, S.-H.; Chen, F.-Q.; Schacht, J. Activation of cell death pathways in the inner ear of the aging CBA/J mouse. Hear. Res. 2009, 254, 92-99. [CrossRef] [PubMed]

7. Baker, K.; Staecker, H. Low Dose Oxidative Stress Induces Mitochondrial Damage in Hair Cells. Anat. Rec. 2012, 295, 1868-1876. [CrossRef]

8. Neri, S.; Signorelli, S.; Pulvirenti, D.; Mauceri, B.; Cilio, D.; Bordonaro, F.; Abate, G.; Interlandi, D.; Misseri, M.; Ignaccolo, L.; et al. Oxidative stress, nitric oxide, endothelial dysfunction and tinnitus. Free Radic. Res. 2006, 40, 615-618. [CrossRef]

9. Celik, M.; Koyuncu, İ. A Comprehensive Study of Oxidative Stress in Tinnitus Patients. Indian J. Otolaryngol. Head Neck Surg. 2018, 70, 521-526. [CrossRef]

10. Ekinci, A.; Kamasak, K. Evaluation of serum prolidase enzyme activity and oxidative stress in patients with tinnitus. Braz. J. Otorhinolaryngol. 2019, in press. [CrossRef]

11. Koç, S.; Akyüz, S.; Somuk, B.T.; Soyalic, H.; Yılmaz, B.; Taskin, A.; Bilinc, H.; Aksoy, N. Paraoxonase Activity and Oxidative Status in Patients with Tinnitus. J. Audiol. Otol. 2016, 20, 17-21. [CrossRef] [PubMed]

12. Pawlak-Osińska, K.; Kaźmierczak, H.; Marzec, M.; Kupczyk, D.; Bilski, R.; Mikołajewska, E.; Mikołajewski, D.; Augustyńska, B. Assessment of the State of the Natural Antioxidant Barrier of a Body in Patients Complaining about the Presence of Tinnitus. Oxidative Med. Cell. Longev. 2018, 2018, 1439575. [CrossRef] [PubMed] 
13. Procházková, K.; Šejna, I.; Skutil, J.; Hahn, A. Ginkgo biloba extract EGb 761@versus pentoxifylline in chronic tinnitus: A randomized, double-blind clinical trial. Int. J. Clin. Pharm. 2018, 40, 1335-1341. [CrossRef] [PubMed]

14. Morgenstern, C.; Biermann, E. The efficacy of Ginkgo special extract EGb 761 in patients with tinnitus. Int. J. Clin. Pharmacol. Ther. 2002, 40, 188-197. [CrossRef]

15. Savastano, M.; Brescia, G.; Marioni, G. Antioxidant Therapy in Idiopathic Tinnitus: Preliminary Outcomes. Arch. Med. Res. 2007, 38, 456-459. [CrossRef]

16. Person, O.C.; Puga, M.E.; da Silva, E.M.; Torloni, M.R. Zinc supplementation for tinnitus. Cochrane Database Syst. Rev. 2016, 2016. [CrossRef]

17. Polanski, J.F.; Soares, A.D.; de Mendonça Cruz, O.L. Antioxidant therapy in the elderly with tinnitus. Braz. J. Otorhinolaryngol. 2016, 82, 269-274. [CrossRef]

18. Xiong, M.; Lai, H.; Yang, C.; Huang, W.; Wang, J.; Fu, X.; He, Q. Comparison of the Protective Effects of Radix Astragali, $\alpha$-Lipoic Acid, and Vitamin E on Acute Acoustic Trauma. Clin. Med. Insights Ear Nose Throat 2012, 5, 25-31. [CrossRef]

19. Karafakioğlu, Y.S. Effects of $\alpha$ lipoic acid on noise induced oxidative stress in rats. Saudi J. Biol. Sci. 2019, 26, 989-994. [CrossRef]

20. Erdem, T.; Bayindir, T.; Filiz, A.; Iraz, M.; Selimoglu, E. The effect of resveratrol on the prevention of cisplatin ototoxicity. Eur. Arch. Otorhinolaryngol. 2012, 269, 2185-2188. [CrossRef]

21. Simsek, G.; Taş, B.M.; Muluk, N.B.; Azman, M.; Kılıç, R. Comparison of the protective efficacy between intratympanic dexamethasone and resveratrol treatments against cisplatin-induced ototoxicity: An experimental study. Eur. Arch. Otorhinolaryngol. 2019, 276, 3287-3293. [CrossRef]

22. Yumusakhuylu, A.C.; Yazici, M.; Sari, M.; Binnetoglu, A.; Kosemihal, E.; Akdas, F.; Sirvanci, S.; Yuksel, M.; Uneri, C.; Tutkun, A. Protective role of resveratrol against cisplatin induced ototoxicity in guinea pigs. Int. J. Pediatr. Otorhinolaryngol. 2012, 76, 404-408. [CrossRef]

23. Li, I.-H.; Shih, J.-H.; Jhao, Y.-T.; Chen, H.-C.; Chiu, C.-H.; Chen, C.-F.F.; Huang, Y.-S.; Shiue, C.-Y.; Ma, K.-H. Regulation of Noise-Induced Loss of Serotonin Transporters with Resveratrol in a Rat Model Using 4-[18F]-ADAM/Small-Animal Positron Emission Tomography. Molecules 2019, 24, 1344. [CrossRef]

24. Seidman, M.D.; Tang, W.; Bai, V.U.; Ahmad, N.; Jiang, H.; Media, J.; Patel, N.; Rubin, C.J.; Standring, R.T. Resveratrol decreases noise-induced cyclooxygenase-2 expression in the rat cochlea. Otolaryngol. Head Neck Surg. 2013, 148, 827-833. [CrossRef]

25. Xiong, H.; Ou, Y.; Xu, Y.; Huang, Q.; Pang, J.; Lai, L.; Zheng, Y. Resveratrol Promotes Recovery of Hearing following Intense Noise Exposure by Enhancing Cochlear SIRT1 Activity. AUD 2017, 22, 303-310. [CrossRef]

26. Joachims, H.Z.; Segal, J.; Golz, A.; Netzer, A.; Goldenberg, D. Antioxidants in treatment of idiopathic sudden hearing loss. Otol. Neurotol. 2003, 24, 572-575. [CrossRef]

27. Quaranta, N.; Dicorato, A.; Matera, V.; D’Elia, A.; Quaranta, A. The effect of alpha-lipoic acid on temporary threshold shift in humans: A preliminary study. Acta Otorhinolaryngol. Ital. 2012, 32, 380-385.

28. Institute of Medicine (US). Dietary Reference Intakes: The Essential Guide to Nutrient Requirements; National Academies Press: Washington, DC, USA, 2006; ISBN 978-0-309-15742-1.

29. Institute of Medicine (US). Using the Tolerable Upper Intake Level for Nutrient Assessment of Groups. In Dietary Reference Intakes: Applications in Dietary Assessment; National Academies Press: Washington, DC, USA, 2000; Chapter 6; pp. 113-126.

30. Kapul, A.; Zubova, E.; Torgaev, S.; Drobchik, V. Pure-tone Audiometer. J. Phys. Conf. Ser. 2017, 881, 012010. [CrossRef]

31. Rodríguez Valiente, A.; Trinidad, A.; García Berrocal, J.R.; Górriz, C.; Ramírez Camacho, R. Extended high-frequency $(9-20 \mathrm{kHz})$ audiometry reference thresholds in 645 healthy subjects. Int. J. Audiol. 2014, 53, 531-545. [CrossRef]

32. Henry, J.A.; Meikle, M.B. Psychoacoustic Measures of Tinnitus. J. Am. Acad. Audiol. 2000, 11, $138-155$.

33. Newman, C.W.; Jacobson, G.P.; Spitzer, J.B. Development of the Tinnitus Handicap Inventory. Arch. Otolaryngol. Head Neck Surg. 1996, 122, 143-148. [CrossRef]

34. Figueiredo, R.R.; de Azevedo, A.A.; de Mello Oliveira, P. Correlation analysis of the visual-analogue scale and the Tinnitus Handicap Inventory in tinnitus patients. Braz. J. Otorhinolaryngol. 2009, 75, 76-79. [CrossRef] 
35. Meikle, M.; Henry, J.; Griest, S.; Stewart, B.; Abrams, H.; McArdle, R.; Myers, P.; Newman, C.; Sandridge, S.; Turk, D.; et al. The Tinnitus Functional Index: Development of a New Clinical Measure for Chronic, Intrusive Tinnitus. Ear Hear. 2012, 33, 153-176. [CrossRef]

36. Willett, W.C.; Sampson, L.; Stampfer, M.J.; Rosner, B.; Bain, C.; Witschi, J.; Hennekens, C.H.; Speizer, F.E. Reproducibility and validity of a semiquantitative food frequency questionnaire. Am. J. Epidemiol. 1985, 122, 51-65. [CrossRef]

37. Panagiotakos, D.B.; Pitsavos, C.; Stefanadis, C. Dietary patterns: A Mediterranean diet score and its relation to clinical and biological markers of cardiovascular disease risk. Nutr. Metab. Cardiovasc. Dis. 2006, 16, 559-568. [CrossRef]

38. Craig, C.L.; Marshall, A.L.; Sjöström, M.; Bauman, A.E.; Booth, M.L.; Ainsworth, B.E.; Pratt, M.; Ekelund, U.; Yngve, A.; Sallis, J.F.; et al. International Physical Activity Questionnaire: 12-Country Reliability and Validity. Med. Sci. Sports Exerc. 2003, 35, 1381-1395. [CrossRef]

39. Fountoulakis, K.; Iacovides, A.; Kleanthous, S.; Samolis, S.; Kaprinis, S.G.; Sitzoglou, K.; St Kaprinis, G.; Bech, P. Reliability, Validity and Psychometric Properties of the Greek Translation of the Center for Epidemiological Studies-Depression (CES-D) Scale. BMC Psychiatry 2001, 1, 3. [CrossRef]

40. Michopoulos, I.; Douzenis, A.; Kalkavoura, C.; Christodoulou, C.; Michalopoulou, P.; Kalemi, G.; Fineti, K.; Patapis, P.; Protopapas, K.; Lykouras, L. Hospital Anxiety and Depression Scale (HADS): Validation in a Greek general hospital sample. Ann. Gen. Psychiatry 2008, 7, 4. [CrossRef]

41. Artiss, J.D.; Vinogradov, S.; Zak, B. Spectrophotometric study of several sensitive reagents for serum iron. Clin. Biochem. 1981, 14, 311-315. [CrossRef]

42. Mann, C.K.; Yoe, J.H. Spectrophotometric Determination of Magnesium with Sodium 1-Azo-2-hydroxy-3-(2,4-dimethylcarboxanilido)-naphthalene-1'-(2-hydroxybenzene-5-sulfonate). Anal. Chem. 1956, 28, 202-205. [CrossRef]

43. Langguth, B.; Goodey, R.; Azevedo, A.; Bjorne, A.; Cacace, A.; Crocetti, A.; Del Bo, L.; De Ridder, D.; Diges, I.; Elbert, T.; et al. Consensus for tinnitus patient assessment and treatment outcome measurement: Tinnitus Research Initiative meeting, Regensburg, July 2006. Prog. Brain Res. 2007, 166, 525-536.

44. Hiller, W.; Goebel, G. Factors influencing tinnitus loudness and annoyance. Arch. Otolaryngol. Head Neck Surg. 2006, 132, 1323-1330. [CrossRef]

45. Landgrebe, M.; Azevedo, A.; Baguley, D.; Bauer, C.; Cacace, A.; Coelho, C.; Dornhoffer, J.; Figueiredo, R.; Flor, H.; Hajak, G.; et al. Methodological aspects of clinical trials in tinnitus: A proposal for an international standard. J. Psychosom. Res. 2012, 73, 112-121. [CrossRef]

46. Zeman, F.; Koller, M.; Figueiredo, R.; Aazevedo, A.; Rates, M.; Coelho, C.; Kleinjung, T.; de Ridder, D.; Langguth, B.; Landgrebe, M. Tinnitus Handicap Inventory for Evaluating Treatment Effects: Which Changes Are Clinically Relevant? Otolaryngol. Head Neck Surg. 2011, 145, 282-287. [CrossRef]

47. EFSA Panel on Dietetic Products, Nutrition and Allergies (NDA). Guidance on the scientific requirements for health claims related to antioxidants, oxidative damage and cardiovascular health. EFSA J. 2011, 9, 2474. [CrossRef]

48. Chang, J.W.; Lee, E.K.; Kim, T.H.; Min, W.K.; Chun, S.; Lee, K.-U.; Kim, S.B.; Park, J.S. Effects of $\alpha$-Lipoic Acid on the Plasma Levels of Asymmetric Dimethylarginine in Diabetic End-Stage Renal Disease Patients on Hemodialysis: A Pilot Study. AJN 2007, 27, 70-74. [CrossRef]

49. Kinlay, S.; Behrendt, D.; Fang, J.C.; Delagrange, D.; Morrow, J.; Witztum, J.L.; Rifai, N.; Selwyn, A.P.; Creager, M.A.; Ganz, P. Long-term effect of combined vitamins $\mathrm{E}$ and $\mathrm{C}$ on coronary and peripheral endothelial function. J. Am. Coll. Cardiol. 2004, 43, 629-634. [CrossRef]

50. Kim, Y.J.; Ahn, Y.H.; Lim, Y.; Kim, J.Y.; Kim, J.; Kwon, O. Daily Nutritional Dose Supplementation with Antioxidant Nutrients and Phytochemicals Improves DNA and LDL Stability: A Double-Blind, Randomized, and Placebo-Controlled Trial. Nutrients 2013, 5, 5218-5232. [CrossRef]

51. Kolahi, S.; Mirtaheri, E.; Pourghasem Gargari, B.; Khabbazi, A.; Hajalilou, M.; Asghari-Jafarabadi, M.; Mesgari Abbasi, M. Oral administration of alpha-lipoic acid did not affect lipid peroxidation and antioxidant biomarkers in rheumatoid arthritis patients. Int. J. Vitam. Nutr. Res. 2019, 89, 13-21. [CrossRef]

52. Mendoza-Núñez, V.M.; García-Martínez, B.I.; Rosado-Pérez, J.; Santiago-Osorio, E.; Pedraza-Chaverri, J.; Hernández-Abad, V.J. The Effect of $600 \mathrm{mg}$ Alpha-lipoic Acid Supplementation on Oxidative Stress, Inflammation, and RAGE in Older Adults with Type 2 Diabetes Mellitus. Oxidative Med. Cell. Longev. 2019, 2019, 3276958. [CrossRef] 
53. Serafini, M.; Rio, D.D. Understanding the association between dietary antioxidants, redox status and disease: Is the Total Antioxidant Capacity the right tool? Redox Rep. 2004, 9, 145-152. [CrossRef]

54. Jialal, I.; Fuller, C.J.; Huet, B.A. The effect of alpha-tocopherol supplementation on LDL oxidation. A dose-response study. Arterioscler. Thromb. Vasc. Biol. 1995, 15, 190-198. [CrossRef]

55. Arda, H.N.; Tuncel, U.; Akdogan, O.; Ozluoglu, L.N. The role of zinc in the treatment of tinnitus. Otol. Neurotol. 2003, 24, 86-89. [CrossRef]

56. Coelho, C.; Witt, S.A.; Ji, H.; Hansen, M.R.; Gantz, B.; Tyler, R. Zinc to treat tinnitus in the elderly: A randomized placebo controlled crossover trial. Otol. Neurotol. 2013, 34, 1146-1154. [CrossRef]

57. Pisoschi, A.M.; Pop, A. The role of antioxidants in the chemistry of oxidative stress: A review. Eur. J. Med. Chem. 2015, 97, 55-74. [CrossRef]

58. Shay, K.P.; Moreau, R.F.; Smith, E.J.; Smith, A.R.; Hagen, T.M. Alpha-lipoic acid as a dietary supplement: Molecular mechanisms and therapeutic potential. Biochim. Biophys. Acta 2009, 1790, 1149-1160. [CrossRef]

59. Teichert, J.; Hermann, R.; Ruus, P.; Preiss, R. Plasma Kinetics, Metabolism, and Urinary Excretion of Alpha-Lipoic Acid following Oral Administration in Healthy Volunteers. J. Clin. Pharmacol. 2003, 43, 1257-1267. [CrossRef]

60. Yilmaz, Y.; Toledo, R.T. Major flavonoids in grape seeds and skins: Antioxidant capacity of catechin, epicatechin, and gallic acid. J. Agric. Food Chem. 2004, 52, 255-260. [CrossRef]

61. Noack, V.; Pak, K.; Jalota, R.; Kurabi, A.; Ryan, A.F. An Antioxidant Screen Identifies Candidates for Protection of Cochlear Hair Cells from Gentamicin Toxicity. Front. Cell. Neurosci. 2017, 11, 242. [CrossRef]

62. Seidman, M.D. Effects of Dietary Restriction and Antioxidants on Presbyacusis. Laryngoscope 2000, 110, 727-738. [CrossRef]

63. Tokgöz, S.A.; Vuralkan, E.; Sonbay, N.D.; Çalişkan, M.; Saka, C.; Beşalti, Ö.; Akin, İ. Protective effects of vitamins E, B and C and l-carnitine in the prevention of cisplatin-induced ototoxicity in rats. J. Laryngol. Otol. 2012, 126, 464-469. [CrossRef] [PubMed]

64. Wang, A.; Hou, N.; Bao, D.; Liu, S.; Xu, T. Mechanism of alpha-lipoic acid in attenuating kanamycin-induced ototoxicity. Neural Regen. Res. 2012, 7, 2793-2800. [PubMed]

65. Kim, S.K.; Im, G.J.; An, Y.S.; Lee, S.H.; Jung, H.H.; Park, S.Y. The effects of the antioxidant $\alpha$-tocopherol succinate on cisplatin-induced ototoxicity in HEI-OC1 auditory cells. Int. J. Pediatric Otorhinolaryngol. 2016, 86, 9-14. [CrossRef] [PubMed]

66. Lee, J.S.; Kang, S.U.; Hwang, H.S.; Pyun, J.H.; Choung, Y.H.; Kim, C.H. Epicatechin protects the auditory organ by attenuating cisplatin-induced ototoxicity through inhibition of ERK. Toxicol. Lett. 2010, 199, 308-316. [CrossRef]

67. Li, D.-W.; Wang, Y.-D.; Zhou, S.-Y.; Sun, W.-P. $\alpha$-lipoic acid exerts neuroprotective effects on neuronal cells by upregulating the expression of PCNA via the P53 pathway in neurodegenerative conditions. Mol. Med. Rep. 2016, 14, 4360-4366. [CrossRef]

68. Kennedy, D.O. B Vitamins and the Brain: Mechanisms, Dose and Efficacy-A Review. Nutrients 2016, 8, 68. [CrossRef]

69. Houston, D.K.; Johnson, M.A.; Nozza, R.J.; Gunter, E.W.; Shea, K.J.; Cutler, G.M.; Edmonds, J.T. Age-related hearing loss, vitamin B-12, and folate in elderly women. Am. J. Clin. Nutr. 1999, 69, 564-571. [CrossRef]

70. Martínez-Vega, R.; Garrido, F.; Partearroyo, T.; Cediel, R.; Zeisel, S.H.; Martínez-Álvarez, C.; Varela-Moreiras, G.; Varela-Nieto, I.; Pajares, M.A. Folic acid deficiency induces premature hearing loss through mechanisms involving cochlear oxidative stress and impairment of homocysteine metabolism. FASEB J. 2014, 29, 418-432. [CrossRef]

71. De Ridder, D.; Vanneste, S.; Adriaenssens, I.; Lee, A.P.K.; Plazier, M.; Menovsky, T.; van der Loo, E.; Van de Heyning, P.; Møller, A. Microvascular decompression for tinnitus: Significant improvement for tinnitus intensity without improvement for distress. A 4-year limit. Neurosurgery 2010, 66, 656-660. [CrossRef]

72. Lopez-Escamez, J.A.; Bibas, T.; Cima, R.F.F.; Van de Heyning, P.; Knipper, M.; Mazurek, B.; Cederroth, C.R. Genetics of tinnitus: An emerging area for molecular diagnosis and drug development. Front. Neurosci. 2016, 10, 377. [CrossRef]

(C) 2019 by the authors. Licensee MDPI, Basel, Switzerland. This article is an open access article distributed under the terms and conditions of the Creative Commons Attribution (CC BY) license (http://creativecommons.org/licenses/by/4.0/). 